Research Article

\title{
Evaluation and Deformation Control Study on the Bias Pressure of Layered Rock Tunnels
}

\author{
Qi Yanli (D), ${ }^{1}$ Wen Shaoquan, ${ }^{1,2}$ Bai Mingzhou $\mathbb{D}^{1,3}$ Shi Hai, ${ }^{1,3,4}$ Li Pengxiang, ${ }^{1}$ Zhou Hao, ${ }^{5}$ \\ and He Bohu' ${ }^{1}$
}

${ }^{1}$ Beijing Jiaotong University, School of Civil Engineering, Beijing 100044, China

${ }^{2}$ Yunnan Infrastructure Investment Co., Ltd., Kunming 650011, China

${ }^{3}$ Beijing Jiaotong University, Laboratory of Track Engineering, Beijing 100044, China

${ }^{4}$ Tsinghua University, State Key Laboratory of Hydro Science and Engineering, Beijing 100084, China

${ }^{5}$ Shaoxing Traffic Engineering Management Center, Shaoxing 312000, China

Correspondence should be addressed to Qi Yanli; 20115066@bjtu.edu.cn and Bai Mingzhou; mzhbai@qq.com

Received 11 March 2021; Revised 12 July 2021; Accepted 23 July 2021; Published 5 August 2021

Academic Editor: Rossana Dimitri

Copyright (C) 2021 Qi Yanli et al. This is an open access article distributed under the Creative Commons Attribution License, which permits unrestricted use, distribution, and reproduction in any medium, provided the original work is properly cited.

\begin{abstract}
In the process of tunnel construction, the bias of layered rock mass tunnels has always been a prominent problem that troubles the construction and safe operation of tunnels. In this paper, a comprehensive method that combines monitoring technology and discrete element (3DEC) numerical simulation is proposed to analyze the deformation characteristics of the surrounding rock in the layered rock tunnel and the deformation law of the bias tunnel. The results indicate that the tunnel surrounding rock deformation in the study area showed the characteristics of bias. Based on the bias mechanism, the surrounding rock deformation law, the construction deformation control, and the optimization measures of layered rock mass in the bias tunnel were studied by means of combining monitoring technology with discrete element (3DEC) numerical simulation. Based on the research results, appropriate methods for controlling the deformation of the surrounding rock of the tunnel with comprehensive consideration of the anchor rod length, anchor rod angle, and anchor rod layout spacing were proposed. The method proposed in this paper could visually reveal the deformation characteristics of the surrounding rock of layered rock tunnels and the deformation law of bias tunnels. It could also better solve the problem of deformation control in the tunnel construction process. This approach provides a novel idea for special layered rock mass tunnel bias evaluation and deformation control parameter optimization and serves as a valuable reference for analogous engineering cases through engineering case analysis.
\end{abstract}

\section{Introduction}

Tunnel construction, one of the most important "sharp swords" used throughout mountains, has been increasing year by year with the growth of traffic construction demand in Southwest China $[1,2]$. In recent years, the Qinghai-Tibet Railway, Sichuan-Tibet Railway, Yunnan-Tibet Railway, and XinjiangTibet Railway have been studied. Bridges and tunnels of the four railways account for more than $80 \%$ of the total length of railway $[3,4]$. At this time, deformation control technology during the tunnel construction and operation period is especially important, primarily the bias pressure evaluation and deformation control of layered rock tunnels.
To study the bias pressure evaluation and deformation control of layered rock tunnels, scholars at home and abroad have conducted a large number of studies to promote theoretical development and provide technical guidance for engineering. These methods are mainly divided into two categories: tunnel bias evaluation methods [5-12] and tunnel deformation control methods [13-22]. The evaluation methods of tunnel bias mainly focus on the formation mechanism, stress-strain distribution law, bias stress ratio, and stability and construction influence of tunnel bias. Zhong et al., based on comparative tests of different excavation methods under bias pressure conditions, understood the stress-strain variation law on the 
surface and in the ground [5]. Guo et al., based on the test principle of ground penetrating radar (GPR), verified the application feasibility for detecting the surrounding rock loose zone, which could provide effective guidance for the excavation and support construction of tunnels [6]. Chen et al., based on a loess tunnel with a large section passing through a lateral slope, simulated and analyzed the impacts of the three tunneling methods of short bench, CD (Center Diaphragm), and CRD (Cross Diaphragm) on lateral slope stability using the FLAC3D numerical model [7]. Liu et al. utilized the bonded-particle method (BPM) to simulate the hydraulic fracturing process in granular materials, and different failure mechanisms were evaluated by analyzing the formation of microcracks [8]. Cao et al. evaluated the construction risk and optimized construction measures of shallow and large-span tunnels beneath expressways, and the feasibility was verified by the numerical calculation software FLAC3D [9]. Yu et al., based on the critical grade and coverage depth corresponding to the condition of the design code of double track railway tunnels, calculated the stress ratios of the symmetrical position of the tunnel by means of numerical simulation [10]. Dai et al. used finite-element analysis to study the different surface dig angles, the deformation process around the tunnel, and the distribution characteristics of tunnel bolts and the plastic zone, which provided some theoretical basis and construction suggestions for tunnel design under topographic biased pressure [11]. Wang et al. quantitatively analyzed the stability of toppling in interlayered rock slopes by using an engineering geology method based on the evolution process [12]. The deformation control methods of tunnels mainly focus on the deformation mechanism, deformation law analysis, deformation control theory and method, and deformation control materials of tunnel bias. Zhang et al., based on mechanical analysis of the construction progress of a double-arched tunnel under unsymmetrical pressure, proposed two types of partial pressure effects, which together influence the loaded state of a double-arched tunnel. One of them results from shallow depth ground partial pressure and is called "terrain partial pressure," and the other is caused by the construction order of the two bores of double-arched tunnels, called "construction progress partial pressure" [13]. Hu et al. integrated an in situ pull-out model test and FLAC3D numerical analysis to study the mechanical behaviors of tunnel anchorages [14]. Lei et al. used similarity theory and fundamental equations of elasticity mechanics, deduced the similarity criterion of model experiments, and designed the experimental program concretely. Through simulating tests of model tunnels with three different bias angles $\left(15^{\circ}, 30^{\circ}\right.$, and $45^{\circ}$ ), the dynamic change law and distribution forms of the surrounding rock pressure and lining stress and the failure mechanism of the lining and surrounding rock of shallowly buried tunnels under unsymmetrical loading were studied [15]. Lai et al., to determine the distortion and load features of bias highways bedded with soft rock and severe distortion, cited the Yi-Ba Highway Lying Buddha Tunnel project in the study; they conducted field tests on two typical cross sections and analyzed the load and support distortion features at the early phase [16]. Lai et al., to analyze the deformation of the tunnel in weak loess, used precision level and convergence gauges to monitor surface settlement, crown settlement, and horizontal convergence in the Dayoushan loess tunnel in situ [17]. Water-sealed underground oil caverns are quite different from conventional underground projects because of their harsher conditions. Therefore, Wei et al. invented a new grouting material based on sulfoaluminate cement (SAC) and studied its properties under pressure circulation [18]. Jin et al., based on the Sunjiagou tunnel in Shanxi province, collected and analyzed field monitoring data using regression analysis by the least square method, and numerical simulation verification was conducted using the finite-element software ANSYS. The law of surrounding rock deformation varying with the slope of a shallow buried unsymmetrical loading tunnel in loess is summarized [19]. Liu et al. presented the concept of multiscale hierarchical digital rock mass models to describe the rock mass, including its structures at different scales and corresponding scale dependence [20]. Liu et al. conducted a theoretical analysis of grouting process in silty fine stratum using a sleeve valve tube; the diffusion behavior of the grout with Bingham fluid characteristics was determined and simulated for different levels of pressure using the discrete element method. Theoretical analysis and numerical calculations were performed to determine the relationships between the grouting pressure, the diffusion radius, and the initial fracture pressure [21]. Huang et al. used the method of field monitoring and measurement combined with MIDAS numerical simulation to analyze and compare the deformation of the surrounding rock and the maximum principal stress in different stages when the tunnel is under different excavation sequences [22].

There are relatively few studies on the tunnel bias evaluation method and the tunnel deformation control method. $\mathrm{Hu}$ et al. adopted the methods of theoretical analysis, numerical simulation, and field measurement to study the distribution characteristics of the plastic zone and displacement field of the surrounding rock of the tunnel, and the relationship between the stress distribution, structural plane distribution, and failure characteristics of the surrounding rock was revealed. In addition, the bolt support scheme is proposed [23].

In this paper, according to the tunnel bias mechanism, appropriate methods for controlling the deformation of the surrounding rock of the tunnel with comprehensive consideration of the anchor rod length, anchor rod angle, and anchor rod layout spacing were proposed. The method proposed in this paper could not only visually reveal the deformation characteristics of the surrounding rock of layered rock tunnels and the deformation law of bias tunnels but also better solve the problem of deformation control in the tunnel construction process. This approach provides a novel idea for special layered rock mass tunnel bias evaluation and deformation control parameter optimization and serves as a valuable reference for analogous engineering cases through engineering case analysis. 


\section{Site Description and Methodology}

To conduct a comprehensive study of the characteristics and mechanism of the tunnel bias problem in layered rock, a comprehensive method that combines monitoring technology with discrete element (3DEC) numerical simulation is proposed. Based on the aforementioned research, prevention and treatment measures were proposed to solve the problem of tunnel bias in layered rock. The corresponding flowchart is shown in Figure 1.

2.1. Engineering Background. The Yitou tunnel is located in Zhaotong city, Yunnan province, China. The geographical location of the study area and the longitudinal section of the formation lithology in the entrance section of the Yitou tunnel are shown in Figures 2 and 3. The topography of the study area belongs to a medium and low mountain landform, with great relief. The tunnel area has an overall eastwest mountain trend, along which the highest elevation is $1,806 \mathrm{~m}$ and the lowest elevation is $1,607 \mathrm{~m}$; therefore, the relative elevation difference is 119 meters. For the convenience of construction, pedestrian tunnels were excavated along the direction of the tunnel construction, as shown in Figure 3.

The left line starting and ending pile numbers are $\mathrm{ZK} 88+775$ and ZK89 + 680, and the line is $905 \mathrm{~m}$ long; the right line starting and ending pile numbers are YK $88+815$ and YK89+690, and the line is $875 \mathrm{~m}$ long. The tunnel is two-way and has four highways, and the distance between the left and right lines of the tunnel is approximately $20 \mathrm{~m}$ to $35 \mathrm{~m}$. The tunnel is located between the Sichuan-Yunnan meridional tectonic belt and the New Sichuan-Guizhou meridional tectonic belt. The structure is relatively developed in the region, and the overall structural features are trending from northeast to southwest. The entrance and exit of the tunnel are located on the mountain slope, with relatively steep terrain and a natural slope of $40-50^{\circ}$ and $35^{\circ}-50^{\circ}$, respectively. The vegetation on the ground is relatively developed, and the visual condition is poor.

As shown in the field geological mapping data, the stratigraphic structures revealed by the boreholes in the study area are quaternary strata $(Q)$ and different regoliths of siltstone of the Feixianguan Formation in the Lower Triassic $\left(T_{1}^{f}\right)$ from top to bottom. The surrounding rock of the tunnel zone is mainly siltstone of the Feixianguan Formation $\left(T_{1}^{f}\right)$, which is a typical layered rock structure. According to the analysis of the monitoring data, the deformation is large and irregular, and it is subjected to the joint action of geological bias (produced by attitude of rock formation) and topographic bias (produced by topography). The problem of tunnel bias in layered rock in this area demands a prompt solution.

2.2. Monitoring Data and Analysis. Tunnel construction causes significant deformation of the surrounding rock, which results in a serious threat to the stability of the surrounding rock. The monitoring data provide data support for the prevention and control of the stability of the rock deformation surrounding the tunnel.

The tunnel excavation sequence is first left (shallow buried side) and then right (deep buried side). Section ZK88 +815 in the left tunnel and section YK88+835 in the right tunnel are in the same section. The reserved deformation of this section is $150 \mathrm{~mm}$, which is also the maximum allowable displacement value $\mathrm{U}_{0}$. The settlement diagram of the vault is shown in Figure 4. The horizontal convergence values of $\mathrm{AE}$ survey lines at the lower step of three continuous monitoring sections in the left and right tunnels were selected for analysis. The sections of the left and right tunnel are in the same section, and the convergent cumulative deformation of the section is shown in Figure 5.

As shown in Figure 4, the deformation displacements of the left and right tunnels are approximately $120 \mathrm{~mm}$, greater than $2 / 3 \mathrm{U}_{0}$ and less than $\mathrm{U}_{0}$, whose management level is $\mathrm{I}$, and special measures must be taken. The large deformation displacement of the surrounding rock is mainly because the monitoring section is located at the entrance of the tunnel and the rock strata are strongly weathered.

The displacement changes of the three measuring points are inconsistent: the deformation of measuring point $B$ is larger, followed by measuring points $C$ and $D$, which show bias characteristics. There are three reasons for the inconsistent displacement changes of the measured points: first, it is the geological bias, whose section is layered siltstone with a thickness of approximately $0.4 \mathrm{~m}$, and the occurrence of the rock strata is $2^{\circ} \angle 6^{\circ}$; second, there is terrain bias, where the terrain is a gentle tilt to the right; third, the buried depth of the left tunnel is shallow and is excavated first, which has an unloading effect on the rock mass of the right tunnel, leading to the larger deformation of the right cave. Of course, the main reason for the inconsistency of displacement of the measured point is geological and topographic bias.

Within 15 days after excavation, the accumulated deformation of the vault was nearly $2 / 3 \mathrm{U}_{0}$, and the two tunnels tended to be stable approximately 20 days after excavation, among which the left tunnel reached a stable state earlier than the right tunnel.

As shown in Figure 5, the deformation of small piles in the same section is larger, and the horizontal deformation decreases as the tunnel is excavated deeper. Approximately 20 days after excavation, the horizontal convergence of the two tunnels is stable, which is consistent with the stable time of the settlement deformation of the vault.

The vault settlement of siltstone in the tunnel area is much greater than the horizontal deformation. The horizontal convergence of different tunnel sections has a large difference; the horizontal convergence deformation is irregular, and it has a large rate of change, which is caused by the anisotropy of layered rock mass deformation. There is a movement between the structural plane and rock mass, and there are also differences in strength between the structural planes. Therefore, one of the difficulties in studying the tunnel deformation of layered rock mass is to study the constitutive relation model of structural plane deformation and the shear strength model of the structural plane. 


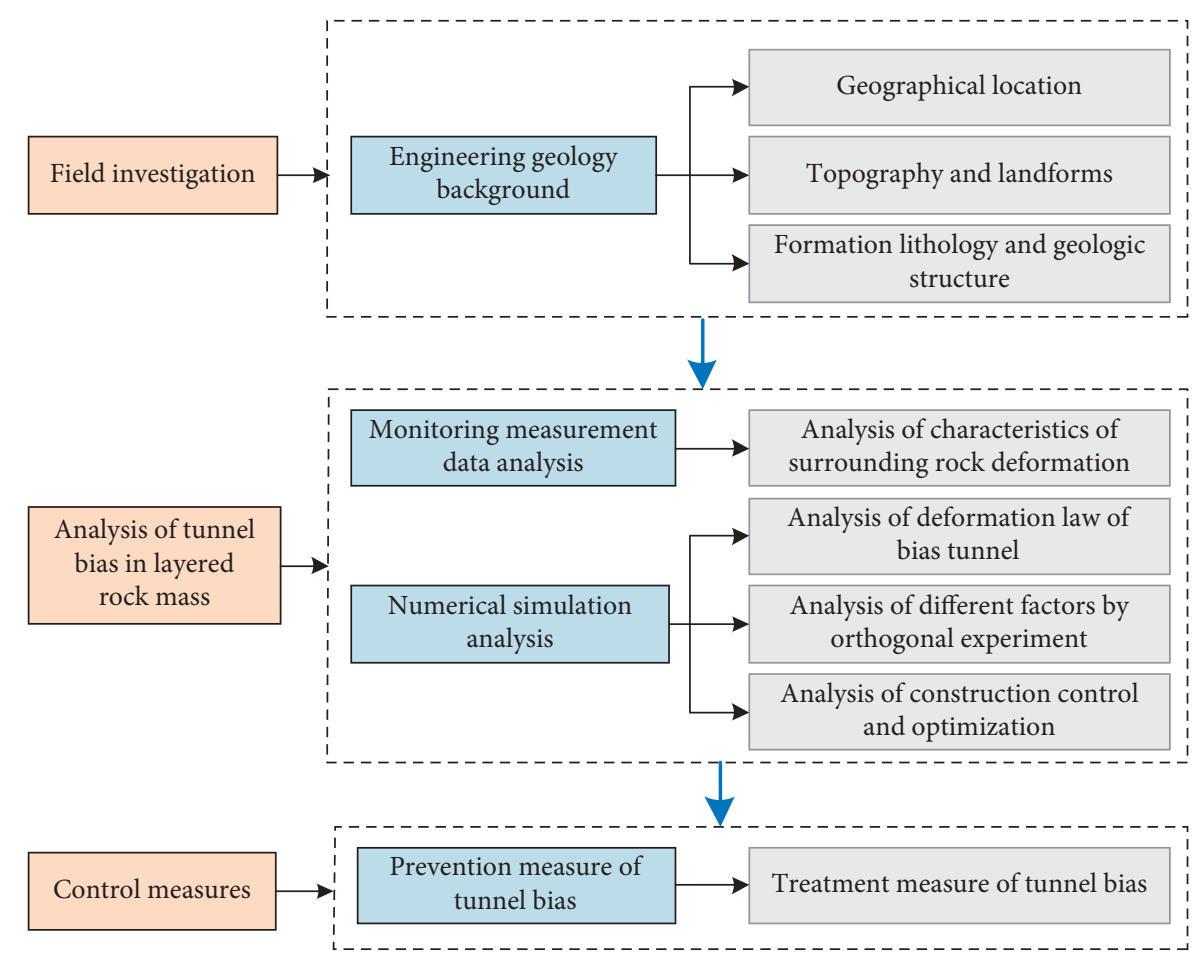

FIGURE 1: Flowchart of the analyses conducted in this study.

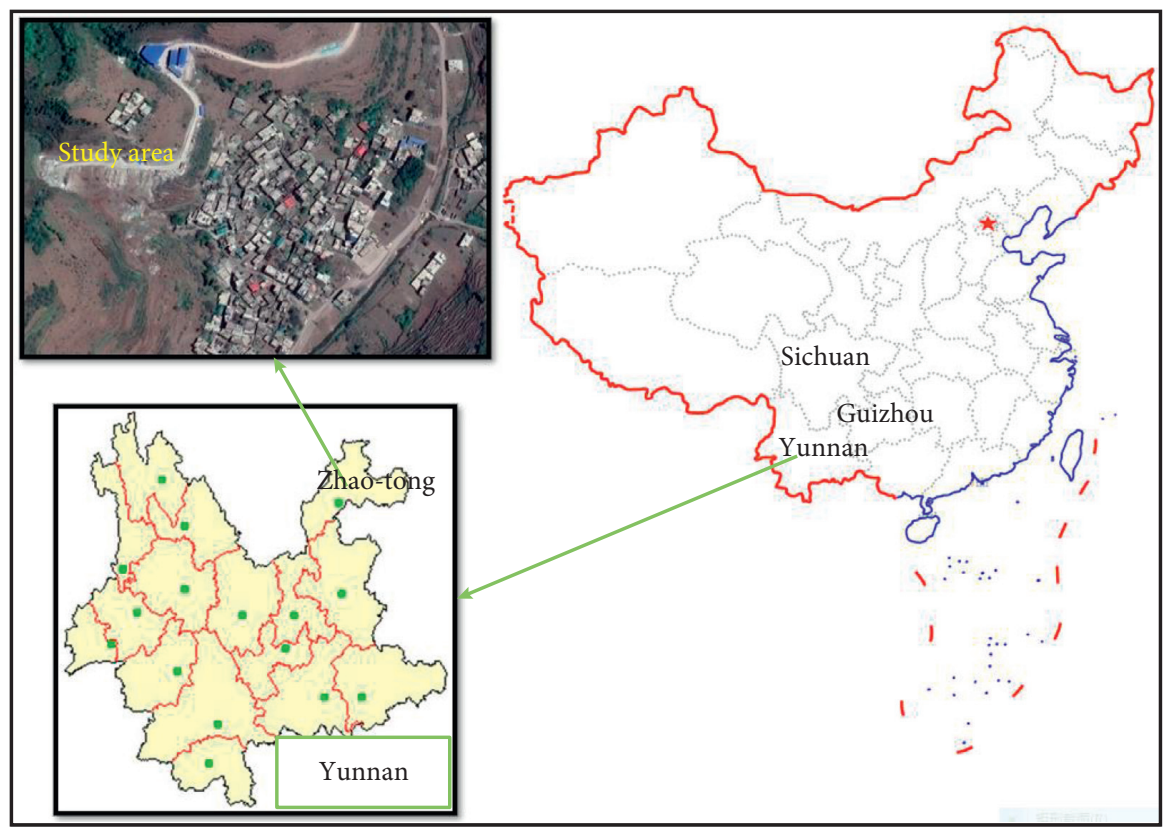

Figure 2: Geographical location of the study area.

Regarding the analysis of the deformation characteristics of the surrounding rock, the settlement deformation of the vaults of the left and right tunnels in the study area is much larger than the horizontal displacement deformation. The settlement deformation value of the vault is greater than $2 / 3$ $\mathrm{U}_{0}$ and less than $\mathrm{U}_{0}\left(\mathrm{U}_{0}\right.$ is the maximum allowable displacement value). Both the vault settlement deformation and horizontal displacement deformation reached a stable state approximately 20 days after the tunnel excavation. The settlement deformation of the vaults of the left and right tunnels shows the characteristics of bias. There are three reasons for this circumstance. The first is geological bias. The second is terrain bias. The third is that the buried depth of the right tunnel is shallow and is excavated first, which has an unloading effect on the rock mass of the left tunnel, leading to the larger deformation of the right tunnel. 


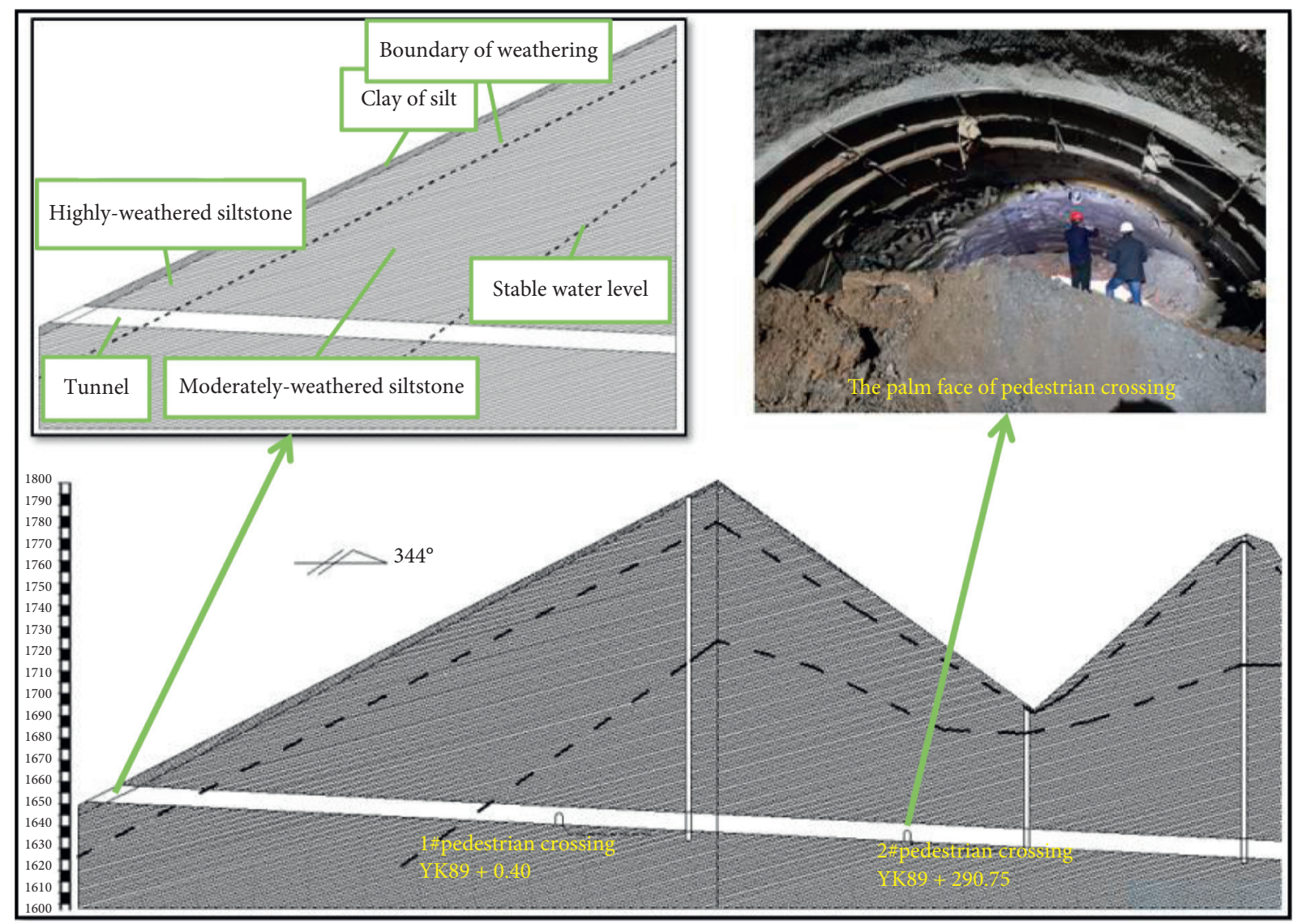

Clay of silt

Siltstone

FIGURE 3: Longitudinal profile of the formation lithology of the entrance section of the Yitou tunnel.

\subsection{Theoretical Analysis and Methodology}

\subsubsection{Theoretical Model and Numerical Simulation Model}

\section{(1) Theoretical Model}

(1) The constitutive relation model of structural plane deformation

Sun [24] divided the structural planes into hard structural planes and weak structural planes or weak interlayers. The rock mass structure plane can be divided into stratified planes, fault fracture zones, and argillaceous interlayers according to its genesis. According to the number of structural planes, they can be divided into single-layer structural planes and multilayer structural planes. The multilayer structural plane can be subdivided into parallel cutting structural planes and different direction structural planes.

The constitutive relation of the structural plane affects the mechanical properties and stability of the rock mass. The deformation law of the structural plane is generally characterized by the stress-displacement relation. The deformation mainly includes the closing or opening deformation perpendicular to the structural plane and the shear slip deformation along the joint plane. Therefore, the constitutive relation of the structural plane is the relation between the stress of the structural plane and its normal and tangential deformation.

There are two stresses on the structure surface: normal stress $\delta$ and shear stress $\tau$, the corresponding normal displacement $\delta_{\mathrm{n}}$ (opening is positive, closing is negative) and tangential displacement $\delta_{s}$. The stress-displacement relationship is expressed as a $2 \times 2$ matrix (stiffness matrix $K$ ):

$$
\left(\begin{array}{l}
\delta \\
\tau
\end{array}\right)=\left\{\begin{array}{cc}
K_{\mathrm{n}} & K_{n s} \\
K_{\mathrm{sn}} & K_{\mathrm{s}}
\end{array}\right\}\left(\begin{array}{c}
\delta_{\mathrm{n}} \\
\delta_{\mathrm{s}}
\end{array}\right)
$$

where $K_{n}$ is the normal stiffness coefficient and represents the effect of normal displacement on normal stress; $K_{\mathrm{s}}$ is the shear stiffness coefficient, indicating the effect of shear displacement on the shear stress; $K_{\mathrm{ns}}$ is the dilatancy coefficient of shear and represents the effect of shear displacement on normal stress; and $K_{\mathrm{sn}}$ represents the effect of normal displacement on shear stress.

Qualitative analysis shows that the influence of normal displacement on shear stress can be ignored 


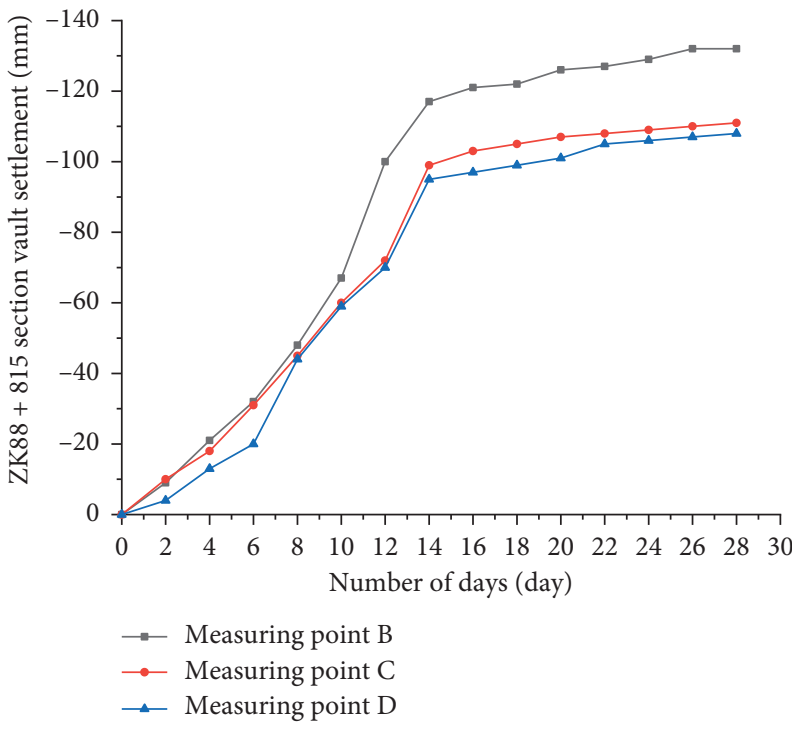

(a)

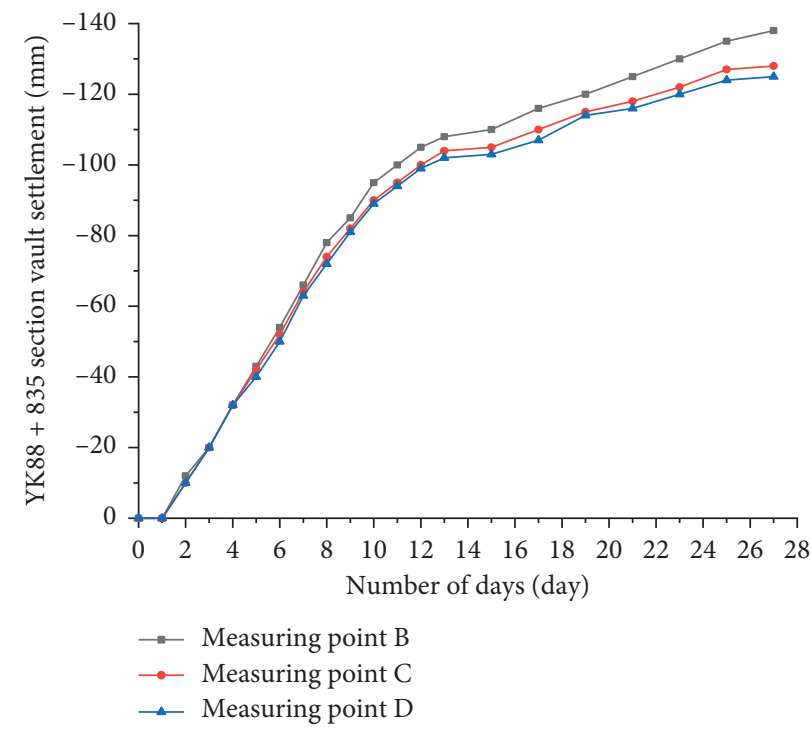

(b)

FIGURE 4: Vault settlement displacement of the left and right tunnels.

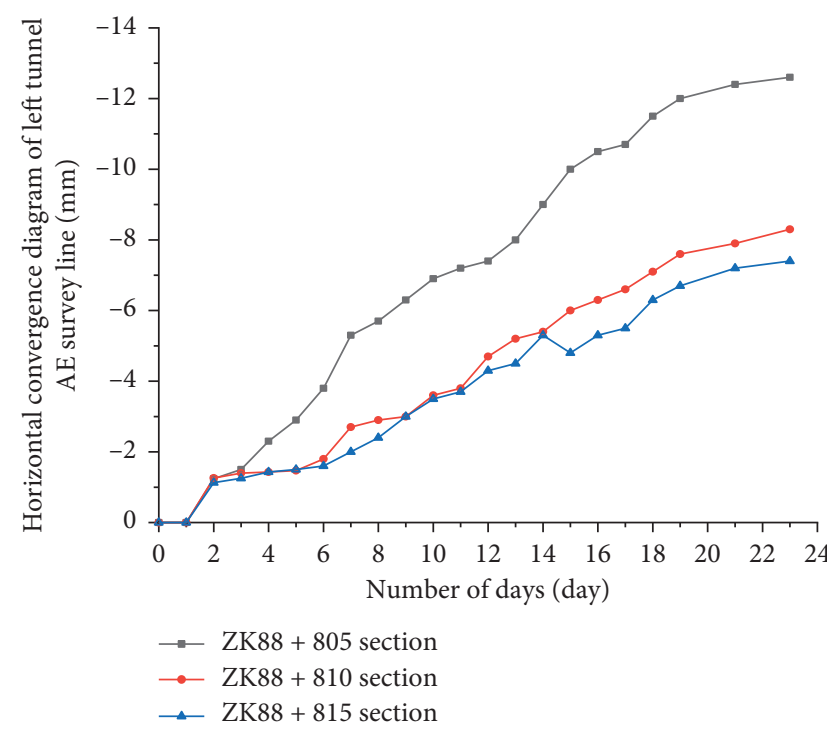

(a)

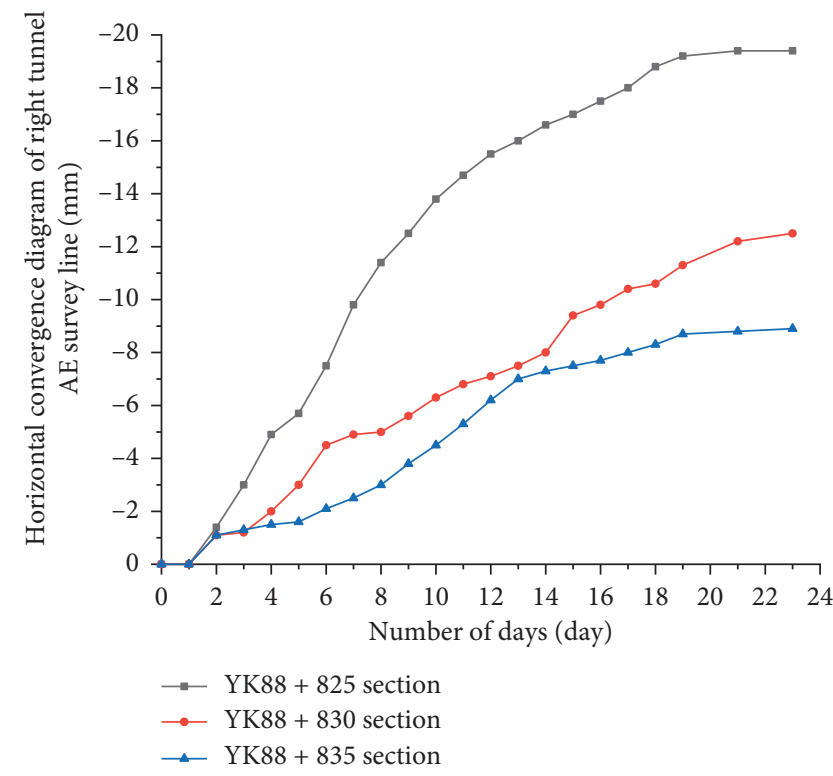

(b)

FIGURE 5: Curve of horizontal convergence of AE line in the lower step of the left and right tunnel at the entrance of Yitou tunnel.

(namely, $K_{\mathrm{sn}}=0$ ) and the other stiffness coefficients are determined by testing. In practice, the stiffness coupling is mostly ignored, and the Goodman element is adopted; namely, $K_{\mathrm{ns}}$ and $K_{\mathrm{sn}}$ are set to 0 . The normal deformation and shear deformation of the structural plane are described by using the normal stiffness $K_{\mathrm{n}}$ and tangential stiffness $K_{\mathrm{s}}$, respectively. Therefore, as shown in (1), to determine the stress-displacement relationship of the structural plane is to determine $K_{\mathrm{n}}$ and $K_{\mathrm{s}}$.
The relation between the stress and displacement of the structural plane is highly nonlinear; the larger the normal stress of the structural plane is, the smaller the relative distance between the structural planes is, and the larger the normal stiffness of the structural plane is. When the normal stress of the structural plane increases to a certain value, the displacement between the structural planes tends to 0 . At the same time, when analyzing the deformation of the structural plane, it is assumed that the structural 
plane cannot be tensile, and the stress-strain relationship is mainly studied for the closed deformation of rock mass under compression. Under the action of tensile stress, the deformation of the structural plane increases rapidly and causes failure.

In addition, the normal stiffness and shear stiffness of the structural plane are related to the compressive strength of the rock block, the roughness of the structural plane, the scale, the initial stress state, and other factors, which are highly nonlinear and random. The stiffness coefficient of the structural plane varies greatly, and its value has a large influence on the deformation of the structural plane.

(2) The shear strength model of the structural plane

The failure of jointed rock mass is mainly shear failure along the jointed plane. The peak shear strength of the jointed plane is the most important mechanical property of the jointed rock mass. In jointed rock mass, the surface of the jointed rock mass often roughly floats, and the shear strength is related to the bonding force, surface state, rock mass strength, and stress state of the structural plane. 3DEC is selected, contact-friction-type joints are used to simulate the contact relationship, and Coulomb slip model is adopted. Assuming that the increment of the normal force vector $F_{\mathrm{n}}$ and the increment of the shear vector $F_{s}$ are proportional to the increment of the normal displacement $u_{\mathrm{n}}$ and the increment of the tangential displacement $u_{\mathrm{s}}$, respectively, in the elastic stage, the contact stiffness coefficients of the normal and tangential springs of the structural plane are $k_{\mathrm{n}}$ and $k_{\mathrm{s}}$, respectively. In addition, assuming that the structural plane cannot be tensile and satisfies Coulomb's law, the following is obtained:

$$
\begin{aligned}
& F_{n}=k_{n} u_{n}, \quad \text { when } u_{n}>0, \\
& F_{n}=0, \quad \text { when } u_{n}>0, \\
& F_{s}=k_{s} u_{s}, \quad \text { when }\left|F_{c s}\right| \leq f\left|F_{c n}\right|+c L, \\
& F_{s}=\operatorname{sign}\left(\dot{u}_{s}\right)\left(f\left|F_{c n}\right|+c L\right), \text { when }\left|F_{c s}\right|>f\left|F_{c n}\right|+c L,
\end{aligned}
$$

where $F_{\mathrm{n}}$ and $F_{\mathrm{s}}$ are the normal and tangential components of the contact force $F_{\mathrm{c}}$, respectively; $k_{\mathrm{n}}$ and $k_{\mathrm{s}}$ are the normal and tangential stiffness of the joints; $u_{n}$ and $u_{s}$ are the relative displacements of the normal and tangential directions of the structure plane, respectively; f and $\mathrm{c}$ are the friction coefficient and cohesive force of the joint material; and $\mathrm{L}$ is the length of the contact surface.

(2) Numerical Simulation Model. The Yitou tunnel is modeled on the entrance ZK88+848-ZK88+880 $($ YK88 $+868-$ YK88 +900) section. Based on the principle of reducing the "boundary effect," the left and right sides of the tunnel model were selected to be 3-5 times the hole diameter from the tunnel boundary, and the lower boundary was 3-5 times the hole height from the bottom of the tunnel, to establish the tunnel model. The horizontal direction (hereinafter referred to as the $X$ direction, positive to the right, "east" direction of the geodetic coordinate system) is $100 \mathrm{~m}$ in length, $Y$ ("north" direction of the geodetic coordinate system) is $32 \mathrm{~m}$ in length, and the vertical direction (hereinafter referred to as the $Z$ direction, positive upward) is $26 \mathrm{~m}$ below the tunnel body. The top is taken as the Earth's surface. In the model, the right tunnel is the tunnel inside the slope in the direction of the tunnel excavation, in other words, the deep buried side. The other is the left tunnel. Based on this arrangement, the 3DEC discrete element calculation model of the Yitou tunnel was established, and its rock layer distribution form is shown in Figure 6. The stratum distributed in the calculation model is mainly siltstone. The finite-element mesh generation is related to the calculation's accuracy. However, dense grids increase the computing time, and thus it is necessary to divide the cells rationally.

\subsubsection{Modeling Parameters and Supporting Structure} Parameters. A typical shallow buried bias section of a layered rock mass was considered. The double tunnels are designed as separate tunnels, with a $30.86 \mathrm{~m}$ layout spacing, $10 \mathrm{~m}$ height, and $12 \mathrm{~m}$ span. As shown in the tunnel design, the rock mass in this section is mainly divided into three types: silty clay with a surface covering thickness of 1-2 m, strongly-moderately weathered siltstone in the lower part, and a surrounding rock strength with IV2 strength. To simplify the calculation, silty clay was considered to be equivalent to siltstone. The basic parameters of the surrounding rock modeling are shown in Tables 1 and 2, the tunnel support structure is equivalent to the concrete strength, and the structural mechanical parameters of the tunnel support structure are shown in Tables 3 and 4 . In addition, for simple modeling, the tunnel bight radius is replaced by a straight line.

\subsubsection{Numerical Simulation Conditions}

(1) Numerical Simulation of the Deformation Law of a Layered Rock Mass Biased Tunnel. As shown in Table 5, 26 conditional models are listed; a total of 28 conditional models were added with no geological origin (only topographic factors) and no topographic and geological factors, to analyze the influence of the layer thickness and the dip angle change on the surrounding rock deformation of the layered rock mass tunnel.

(2) Numerical Simulation of the Orthogonal Experiment under Different Factors. Based on the rock mass and the properties of the structural plane, thickness of the rock strata, dip angle of the rock strata, side slope angle, and buried depth of the tunnel, an orthogonal experiment was designed, and range analysis was conducted on the calculation results. The influence degree and influence trend of each factor on the deformation law of each monitoring point are studied. 


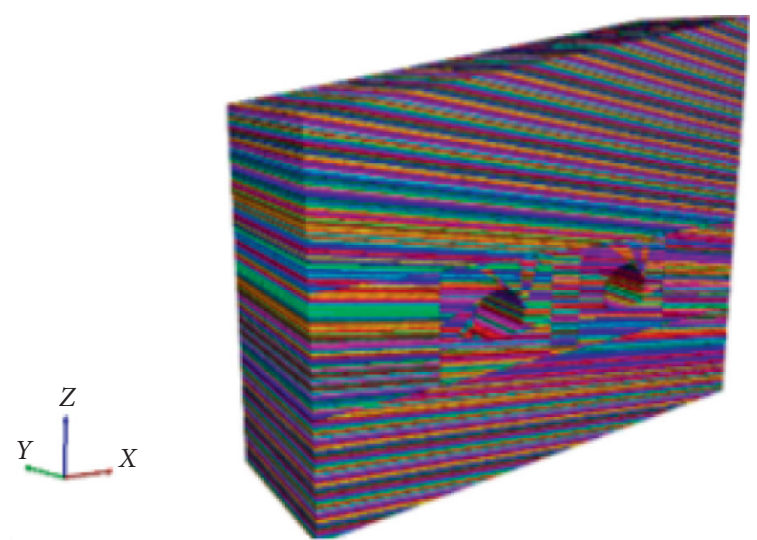

(a)

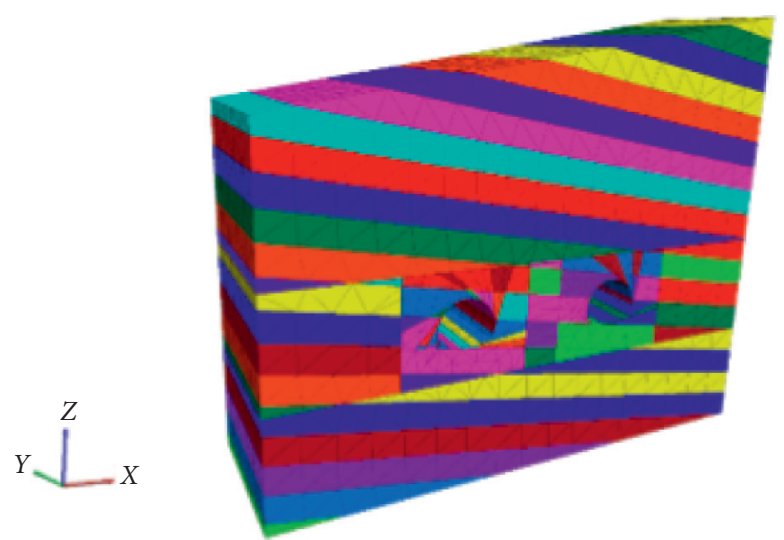

(b)

FIGURE 6: The calculation model of the reverse dip rock with layer thicknesses of (a) $0.5 \mathrm{~m}$ and (b) $5 \mathrm{~m}$.

Table 1: Parameters of the surrounding rock.

\begin{tabular}{lccccccc}
\hline Category & $\begin{array}{c}\text { Elasticity } \\
\text { modulus, } E \\
(\mathrm{MPa})\end{array}$ & $\begin{array}{c}\text { Volume } \\
\text { modulus, } K \\
(\mathrm{MPa})\end{array}$ & $\begin{array}{c}\text { Shear } \\
\text { modulus, } \\
(\mathrm{MPa})\end{array}$ & $\begin{array}{c}\text { Tensile } \\
\text { strength } \\
(\mathrm{MPa})\end{array}$ & $\begin{array}{c}\text { Poisson's } \\
\text { ratio, } \mu\end{array}$ & $\begin{array}{c}\text { Bulk density } \\
\left(\mathrm{kN} / \mathrm{m}^{3}\right)\end{array}$ & $\begin{array}{c}\text { Cohesive } \\
\text { force, } c(\mathrm{MPa})\end{array}$ \\
\hline Siltstone & 1500 & 1250 & 600 & 2 & 0.25 & 23.1 & 0.25 \\
\hline
\end{tabular}

TABLE 2: Parameters of the surrounding structural plane.

\begin{tabular}{|c|c|c|c|c|c|}
\hline Category & $\begin{array}{c}\text { Normal stiffness, } \\
K_{\mathrm{n}}(\mathrm{GPa} / \mathrm{m})\end{array}$ & $\begin{array}{l}\text { Shear stiffness, } \\
K_{\mathrm{s}}(\mathrm{GPa} / \mathrm{m})\end{array}$ & Tensile strength $(\mathrm{MPa})$ & Cohesive force, $C(\mathrm{MPa})$ & Friction angle, $\Phi\left(^{\circ}\right)$ \\
\hline Structural plane & 3 & 1.5 & 0.01 & 50 & 31 \\
\hline
\end{tabular}

TABLE 3: Mechanical parameters of support structure.

\begin{tabular}{lcccccc}
\hline Category & $\begin{array}{c}\text { Elasticity } \\
\text { modulus }(\mathrm{Pa})\end{array}$ & $\begin{array}{c}\text { Strength of grouting slip } \\
(\mathrm{kN} / \mathrm{m} / \mathrm{m})\end{array}$ & $\begin{array}{c}\text { Tensile yield } \\
\text { strength }(\mathrm{kN})\end{array}$ & $\begin{array}{c}\text { Length } \\
(\mathrm{m})\end{array}$ & $\begin{array}{c}\text { Cross-sectional } \\
\text { area }\left(\mathrm{m}^{2}\right)\end{array}$ & $\begin{array}{c}\text { Strength of grouting } \\
\text { bond }(\mathrm{kN} / \mathrm{m})\end{array}$ \\
\hline $\begin{array}{l}\text { Anchor } \\
\text { rod }\end{array}$ & $200 e 3$ & $3.88 e 3$ & 0.32 & 4 & $804 e-6$ & 0.5 \\
\hline
\end{tabular}

TABLE 4: Mechanical parameters of the support structure.

\begin{tabular}{ccccccc}
\hline Category & Elasticity modulus $(\mathrm{Pa})$ & Poisson's ratio $\mu$ & Thickness $(\mathrm{m})$ & Normal stiffness, $K_{\mathrm{n}}(\mathrm{Pa} / \mathrm{m})$ & $\begin{array}{c}\text { Shear stiffness, } \\
K_{\mathrm{s}}(\mathrm{Pa} / \mathrm{m})\end{array}$ & $\begin{array}{c}\text { Coefficient of } \\
\text { friction }\end{array}$ \\
\hline Shotcrete & $20 e 9$ & 0.25 & 0.2 & $1 e 9$ & $1 e 9$ & 50 \\
\hline
\end{tabular}

In forward-leaning rock formations, the orthogonal experimental parameters of layered soft rock bias tunnels are based on geotechnical investigation codes. As shown in orthogonal experimental table $\mathrm{L}_{16}\left(4^{5}\right)$ of 5 factors and 4 horizontal values and the determined experimental parameters, 16 experiments were conducted in total. The specific experimental scheme is shown in Table 6.

(3) Numerical Simulation of Construction Deformation Control and Optimization. The excavation sequence is divided into three modes: first left tunnel (shallow buried side) and then right tunnel (deep buried side), first right tunnel (deep buried side) and then left tunnel (shallow buried side), and alternate excavation. As shown in the working conditions in Table 7, the influence of the excavation sequence on the double-hole tunnel in the layered rock mass was analyzed, and the optimal excavation sequence was determined.

A tunnel failure of layered rock mass is mainly considered a failure of the horizontal rock strata and a large deformation of oblique rock strata. Combined with the comprehensive analysis of various factors, such as the dip angle of the rock strata, the slope angle of the terrain, the buried depth of the tunnel, and the layer thickness, the large deformation area of the layered rock mass tunnel was determined, and the optimized design was established by changing the length and angle of the anchor rod. 
TABLE 5: Conditional models along the dip or tilting to determine the thickness and dip angle.

\begin{tabular}{lccccccc}
\hline \multicolumn{7}{c}{ Different conditions simulated } & \\
\hline Dip angle: $10^{\circ}$ & Tilting/thickness $(\mathrm{m})$ & 0.5 & 1 & 2 & 3 & 4 & 5 \\
Dip angle: $10^{\circ}$ & Along the dip/thickness $(\mathrm{m})$ & 0.5 & 1 & 2 & 3 & 4 & 5 \\
Thickness: $1 \mathrm{~m}$ & Tilting/dip angle $\left(^{\circ}\right)$ & 0 & 15 & 30 & 45 & 60 & 75 \\
Thickness: $1 \mathrm{~m}$ & Along the dip/dip angle $\left({ }^{\circ}\right)$ & 0 & 15 & 30 & 45 & 60 & 75 \\
\hline
\end{tabular}

TABLe 6: Scheme of the orthogonal experiment.

\begin{tabular}{|c|c|c|c|c|c|}
\hline No. & Elastic modulus, $E(\mathrm{GPa})$ & Layer thickness $(\mathrm{m})$ & Dip angle $\left({ }^{\circ}\right)$ & Side slope angle $\left({ }^{\circ}\right)$ & Tunnel depth (m) \\
\hline 1 & 0.5 & 0.5 & 15 & 15 & 10 \\
\hline 2 & 0.5 & 1 & 30 & 25 & 20 \\
\hline 3 & 0.5 & 1.5 & 45 & 35 & 30 \\
\hline 4 & 0.5 & 2 & 60 & 45 & 40 \\
\hline 5 & 1.5 & 0.5 & 30 & 35 & 40 \\
\hline 6 & 1.5 & 1 & 15 & 45 & 30 \\
\hline 7 & 1.5 & 1.5 & 60 & 15 & 20 \\
\hline 8 & 1.5 & 2 & 45 & 25 & 10 \\
\hline 9 & 2.5 & 0.5 & 45 & 45 & 20 \\
\hline 10 & 2.5 & 1 & 60 & 35 & 10 \\
\hline 11 & 2.5 & 1.5 & 15 & 25 & 40 \\
\hline 12 & 2.5 & 2 & 30 & 15 & 30 \\
\hline 13 & 3.5 & 0.5 & 60 & 25 & 30 \\
\hline 14 & 3.5 & 1 & 45 & 15 & 40 \\
\hline 15 & 3.5 & 1.5 & 30 & 45 & 10 \\
\hline 16 & 3.5 & 2 & 15 & 35 & 20 \\
\hline
\end{tabular}

TABLE 7: The influence of the excavation sequence on a double tunnel in the layered rock mass.

\begin{tabular}{lccc}
\hline Working condition of three types & & Main influence factors \\
\hline Topographic bias & $\begin{array}{c}\text { Forward-leaning rock } \\
\text { Backward-leaning } \\
\text { Topographic bias }\end{array}$ & Dip angle of $45^{\circ}$ & Side slope angle of $11^{\circ}$; rock layer of $1 \mathrm{~m}$ thickness \\
Geological bias & Backward-leaning & Rock layer of $5 \mathrm{~m}$ thickness & Side slope angle of $11^{\circ}$; dip angle of $10^{\circ}$ \\
rock & Rock layer of $1 \mathrm{~m}$ thickness & Side slope angle of $11^{\circ}$; dip angle of $10^{\circ}$ \\
\hline
\end{tabular}

Considering the deformation control of the rock surrounding the tunnel when the rock layer is horizontal, the main aim was to study the deformation law of the model caused by changing the length of the bolt. The model is based on a slope angle of $11^{\circ}$, reverse dip, $1 \mathrm{~m}$ thick rock layer, and dip angle of $0^{\circ}$. The study was based on changing the bolt length of the top 5 bolts of the model to $1,2,4,6,7$, and $8 \mathrm{~m}$, and the length of the remaining bolts was $4 \mathrm{~m}$.

Using the deformation control of the surrounding rock of the tunnel when the rock is inclined, the model deformation law caused by changing the bolt angle was mainly studied. The model is based on a slope angle of $11^{\circ}$, reverse dip, $1 \mathrm{~m}$ thick rock layer, and reverse dip of $45^{\circ}$. According to the tendency of the rock strata, the surrounding rocks of the tunnel are divided along the dip side and reverse dip side, as shown in Figure 7. Four working conditions were included in the model: all bolts are arranged radially, all bolts are arranged perpendicular to the rock formation, bolts along the dip side are arranged perpendicular to the rock formation and the remainder are arranged radially, and bolts along the reverse dip side are arranged perpendicular to the rock formation and the remainder are arranged radially. The length of all remaining bolts was $4 \mathrm{~m}$, as shown in Figures 7 and 8 .

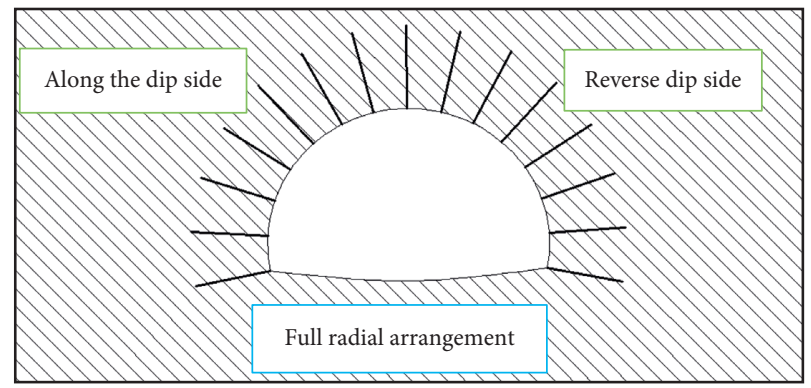

FIgURE 7: Tunnel rock layer and radial anchor rod arrangement.

\section{Result Analysis of Numerical Simulation}

3.1. Analysis of the Deformation Law of Layered Rock Mass Biased Tunnels. The analysis of the tunnel deformation law is mainly based on the $X$ - and $Z$-direction displacement cloud map and monitoring data comparison diagram. The qualitative analysis of the displacement cloud map and quantitative analysis of the monitoring data provide data support for the bias deformation evaluation of the layered rock tunnel. In the double-hole tunnel, the left side of each 


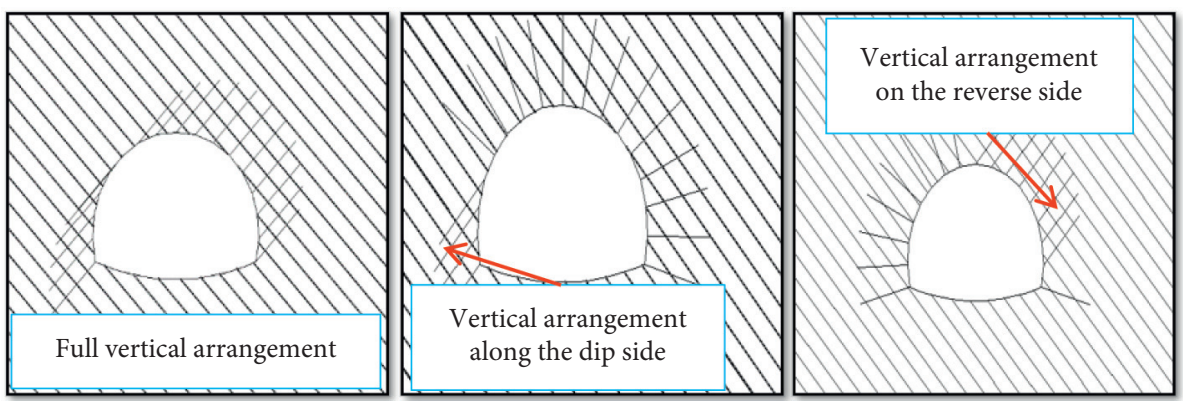

FIgURE 8: Anchor rod arrangement.

tunnel is the area affected by $X$ positive deformation, and the right side is the area affected by $X$ negative deformation.

The simulation results and analysis of the tunnel model with a slope angle of $11^{\circ}$, a rock dip angle of $10^{\circ}$, reverse dip, and rock thickness of $0.5,1,2,3,4$, and $5 \mathrm{~m}$ are as follows.

When topographic bias existed, the tunnel model $X$ direction displacement cloud map of the thickness change of the reverse dip rock layer was analyzed as follows.

As shown in Figure 9(h), without the influence of topographic and geological factors, the area affected by the horizontal displacement of the tunnel deformation presents a nearly symmetrical distribution in the four directions of the upper left, upper right, lower left, and lower right of the tunnel section.

As shown in Figures 9(a) and 9(h), in the shallow buried side only affected by topographic factors, the positive deformation of $X$ on the left side of the left hole develops at the surface, while the influence of the negative transformation of $X$ on the left side of the right hole decreases.

As shown in Figures 9(a)-9(g), the change in the rock layer thickness can affect the tunnel deformation to different degrees, and the reverse dip rock layer can weaken or offset the influence of the topographic bias. When the rock layer is $5 \mathrm{~m}$ thick, the deformation area of the tunnel is clearly affected by the structural plane; the degree of the Earth's surface impact is significantly reduced, the displacement affected area of the left and right holes is reduced, and the degree of bias caused by topographic bias is reduced. As the thickness of the rock layer further decreases, the control effect of the rock layer is strengthened, which is shown as an increase in the area of the affected area on the right side of the tunnel, and the positive and negative displacement values in the $X$ direction increase. However, the main displacement area moves in the direction controlled by the rock layer, in other words, the deep buried side.

Figure 10 shows that the $X$ displacement of each monitoring point on the two walls of the left tunnel is greater than that of the corresponding monitoring point on the two walls of the right tunnel.

Figures 10(a) and 10(b) show that when the bedding of the rock mass occurs and the layer thickness is $5 \mathrm{~m}$, the displacement value of the left wall of the left and right cavities (i.e., the left wall and the left arch waist of the monitoring point, the same as below) decreases. With the continuous decrease in the rock thickness, the displacement value of the left wall of the left cavity increases continuously. This finding shows that the geological bias caused by the appearance of bedding and the layer thickness of $5 \mathrm{~m}$ weaken the influence of the original topographic bias, but the topographic bias is still in the control position. When the thickness of the layer is $4 \mathrm{~m}$ and decreases continuously, the geological bias completely offsets the topographic bias, and the geological bias control effect increases with the decrease in the thickness of the rock layer. When the thickness of the rock layer is 4-5 m, the influence caused by geological bias offsets only the influence of the topographic bias.

As shown in Figure 10(c), when the bedding of the rock mass occurs and the layer thickness of the right wall of the right tunnel is less than $2 \mathrm{~m}$, the displacement increases with the decrease in the layer thickness and is controlled by geological bias. When the layer thickness of the right wall of the left tunnel is greater than or equal to $4 \mathrm{~m}$, the displacement value increases slightly; when the layer thickness of the right wall of the left tunnel is less than $4 \mathrm{~m}$, the displacement increases greatly with the decrease in the layer thickness. This finding indicates that the geological bias at the right wall of the left hole has offset the topographic bias when the layer thickness of the bedding is $5 \mathrm{~m}$.

As shown in Figure 10(d), when the bedding of the rock mass occurs, the displacement of the right arch waist of the left and right cavities does not change significantly when the layer thickness is greater than or equal to $3 \mathrm{~m}$, while when the layer thickness is less than $3 \mathrm{~m}$, the displacement increases with the decrease in the layer thickness and is controlled by geological bias. The effect of geological bias at a thickness of $2-3 \mathrm{~m}$ almost exactly offsets the effect of topographic bias.

When topographic bias existed, the tunnel model $Z$ direction displacement cloud map of the thickness change of the reverse dip rock layer was analyzed as follows.

As shown in Figure 11(h), the displacement of the tunnel in the $Z$ direction is uniformly and symmetrically distributed without the influence of topographic and bedding factors. The settlement displacement of the arch roof is negative, the inverted arch uplift is a positive displacement, and the inverted arch uplift displacement is greater than that of the arch roof.

As shown in Figures 11(a) and 11(h), the surrounding rock pressure is asymmetric when only topographic factors affect the tunnel, and the $Z$-direction maximum displacement moves to the buried side. 

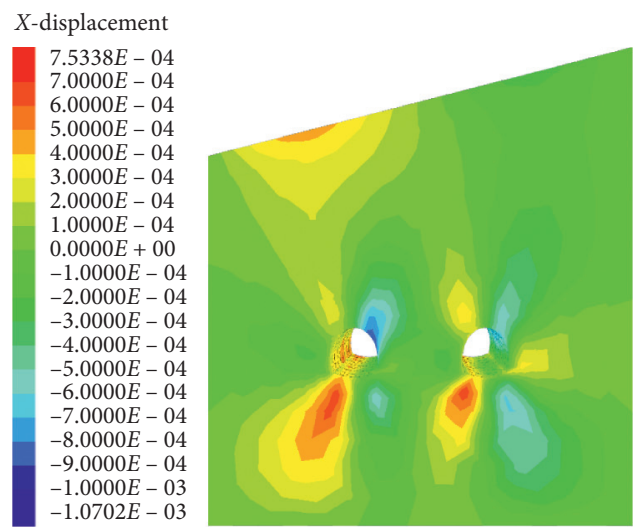

(a)

$X$-displacement
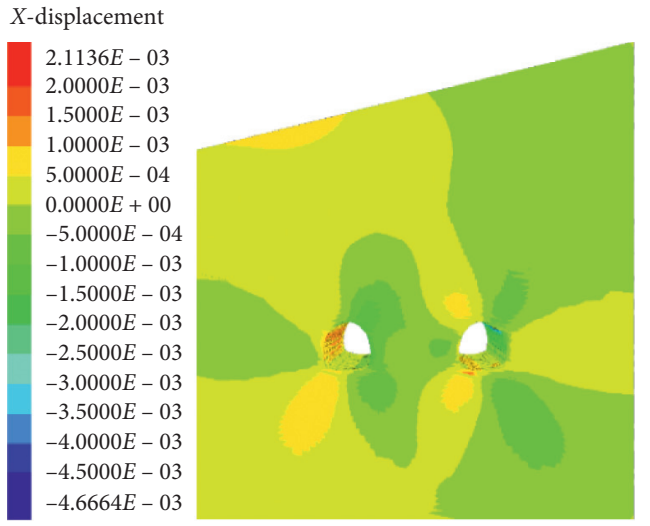

(c)

$X$-displacement

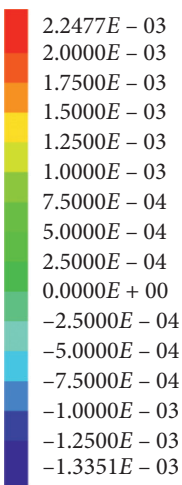

$-1.3351 E-03$

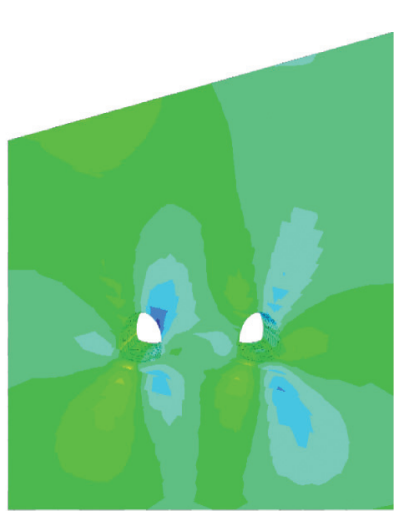

(e)

$X$-displacement

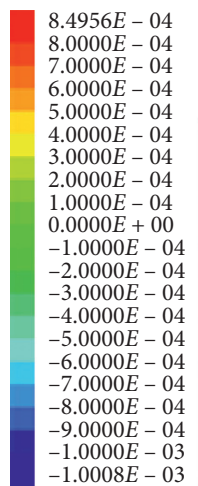

$-1.0008 E-03$

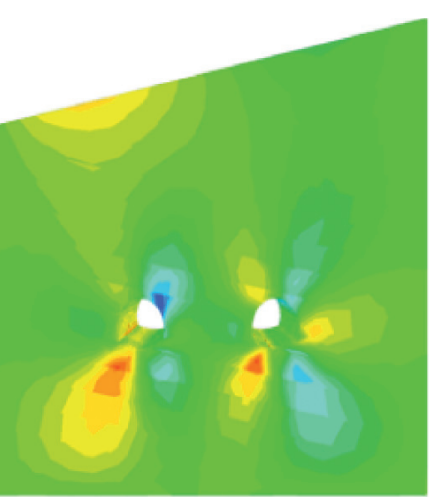

$X$-displacement

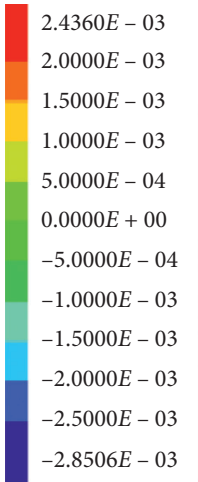

$X$-displacement

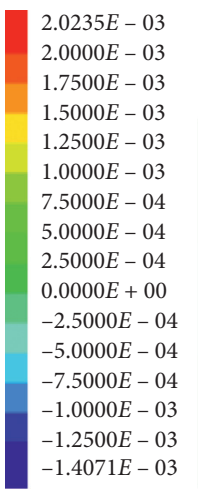

$X$-displacement
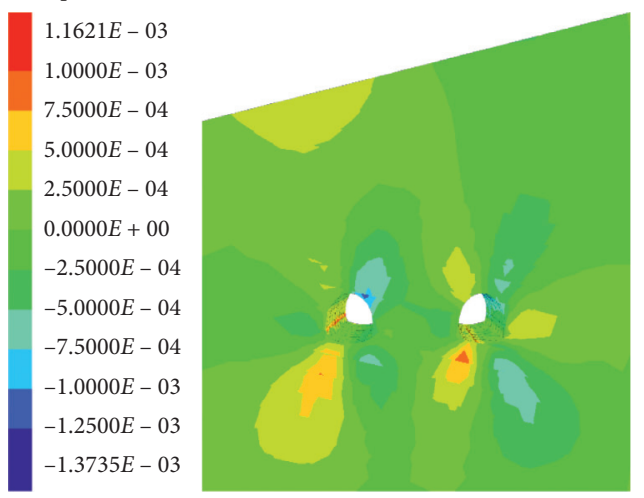

(f)

$X$-displacement

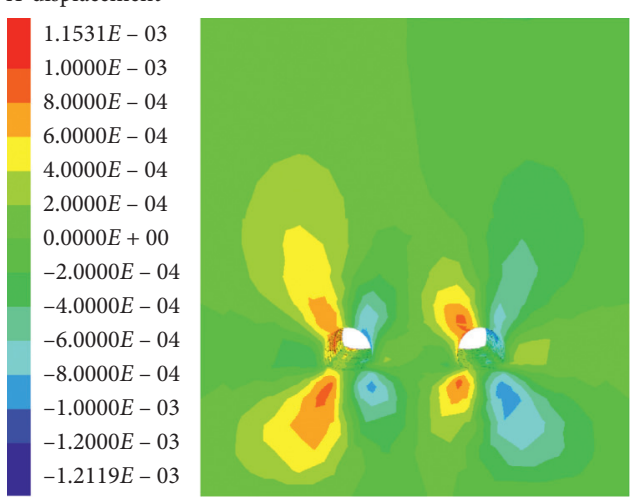

(h)

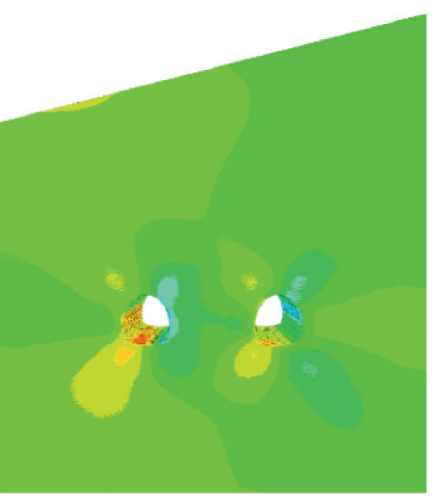

(b)

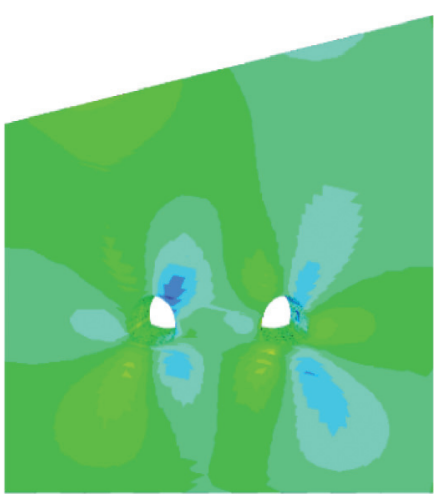

(d) (g)

Figure 9: $X$-direction displacement diagram of change with the thickness of the reverse dip rock layer. (a) Without bedding (terrain only). (b) Layer thickness is $0.5 \mathrm{~m}$. (c) Layer thickness is $1 \mathrm{~m}$. (d) Layer thickness is $2 \mathrm{~m}$. (e) Layer thickness is $3 \mathrm{~m}$. (f) Layer thickness is $4 \mathrm{~m}$. (g) Layer thickness is $5 \mathrm{~m}$. (h) Without bedding or topography. 


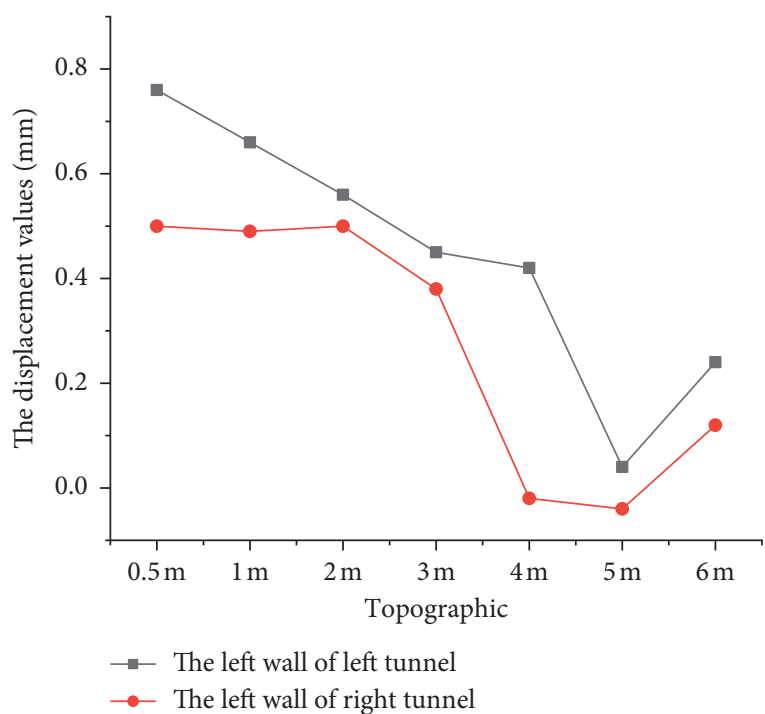

(a)

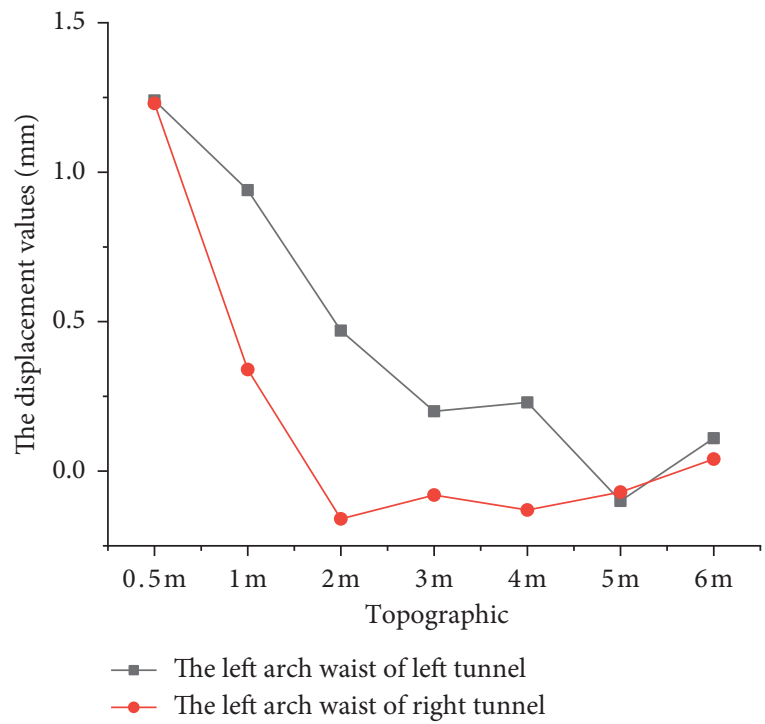

(c)

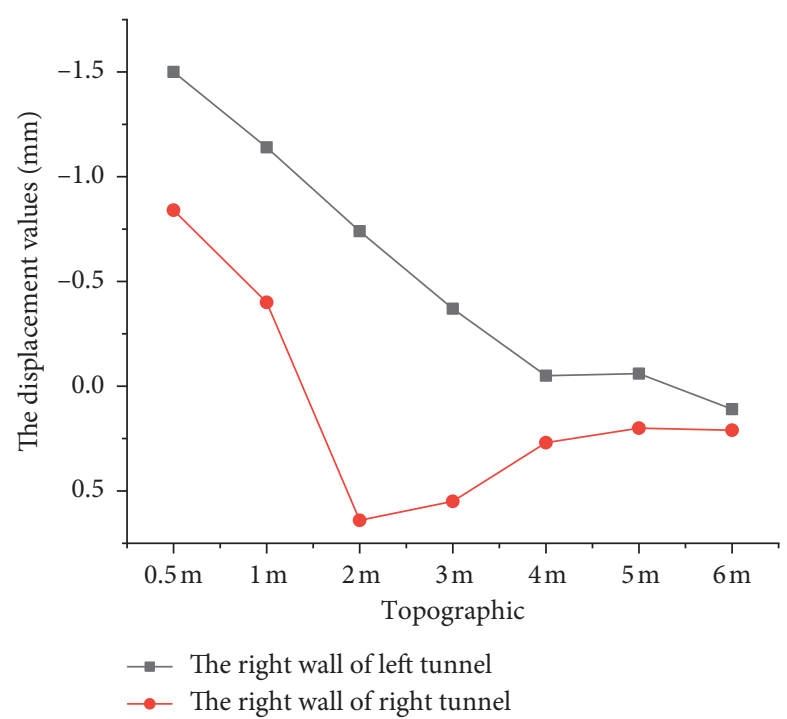

(b)

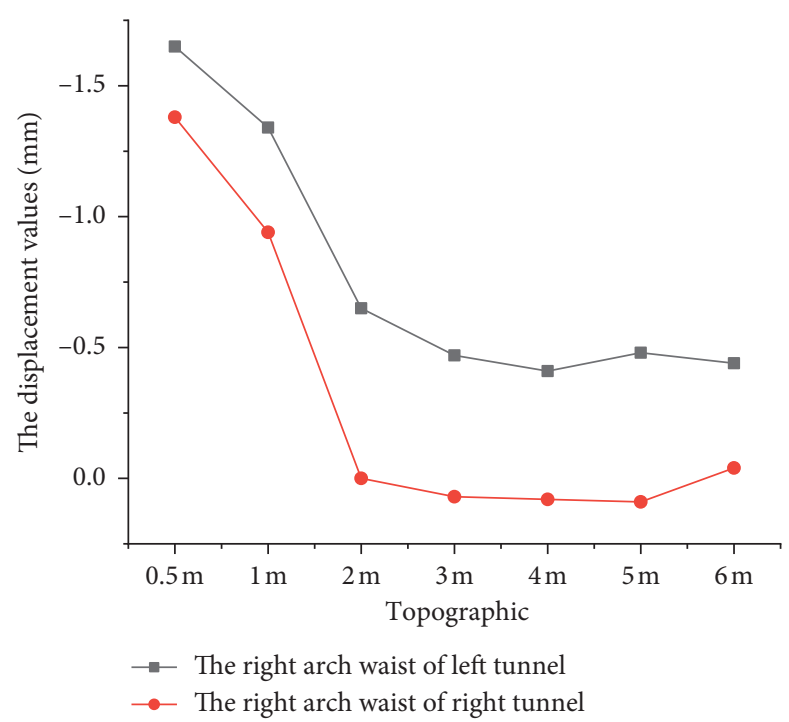

(d)

Figure 10: Comparison diagram of $X$ displacement of different monitoring points in the left and right tunnels. (a) Left wall of the left and right tunnels. (b) Right wall of the left and right tunnels. (c) Left arch waist of the left and right tunnels. (d) Right arch waist of the left and right tunnels.

From Figures 11(a) to 11(g), it can be seen that the maximum positive and negative displacement of the tunnel increase and the morphology of the deformation affected area changes from symmetric to asymmetric when the bedding of the rock mass occurs and the layer thickness is $5 \mathrm{~m}$. The area affected by the large displacement on the deep buried side of the right hole is significantly increased, which indicates that the topographic bias is offset by the geological bias at this time. The geological bias is also under control. With the decrease in the thickness of the rock layer, the maximum positive and negative displacement values of the tunnel gradually increase, and the deformation affected area continuously develops on the deep buried side, which indicates that the geological bias caused by the bedding is constantly enhanced.
Figure 12 shows that the $Z$ displacement of all the monitoring points (the left arch shoulder, right arch shoulder, arch roof, and inverted arch) at the top of the right tunnel is greater than the corresponding monitoring value of the left tunnel. There are two reasons. One reason is that the right tunnel is buried deeper than the left tunnel; the other reason is that, in the inverted rock strata, the rock mass is divided by geological processes. When the width of the rock mass is fixed, the effective length of the surrounding rock mass of the right cave is greater than that of the left cave, and the stress of the right cave is greater than that of the left cave.

Figures 12(a)-12(d) show that when the bedding of the rock mass occurs and the layer thickness is $5 \mathrm{~m}$, the displacement of the monitoring points at the left and right cave arch roof and the inverted arch increases, and the 

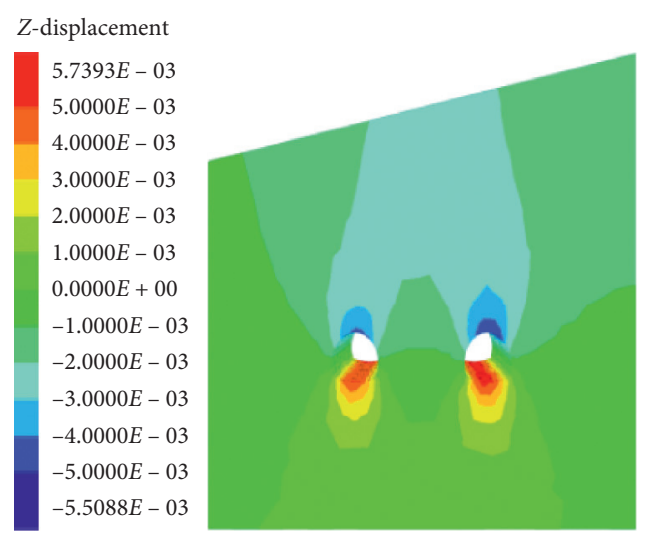

(a)

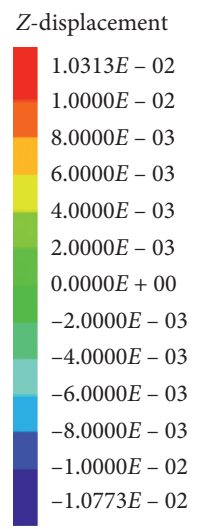

Z-displacement

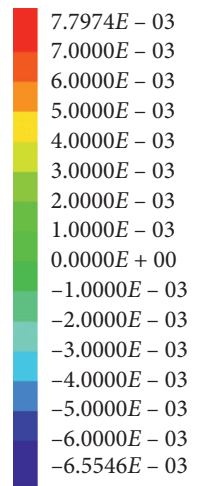

$-6.5546 E-03$

\section{Z-displacement}

$7.2580 E-03$
$7.0000 E-03$
$6.0000 E-03$
$5.0000 E-03$
$4.0000 E-03$
$3.0000 E-03$
$2.0000 E-03$
$1.0000 E-03$
$0.0000 E+00$
$-1.0000 E-03$
$-2.0000 E-03$
$-3.0000 E-03$
$-4.0000 E-03$
$-5.0000 E-03$
$-5.6632 E-03$

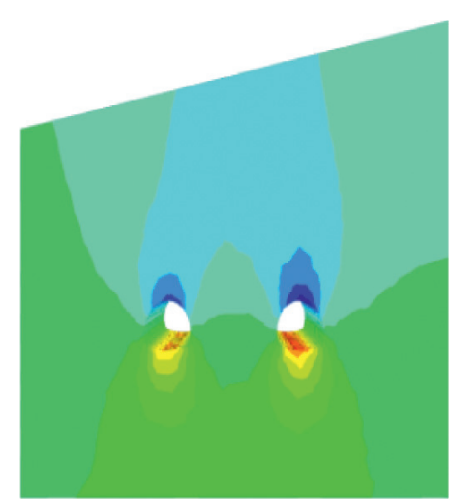

(g)
Z-displacement
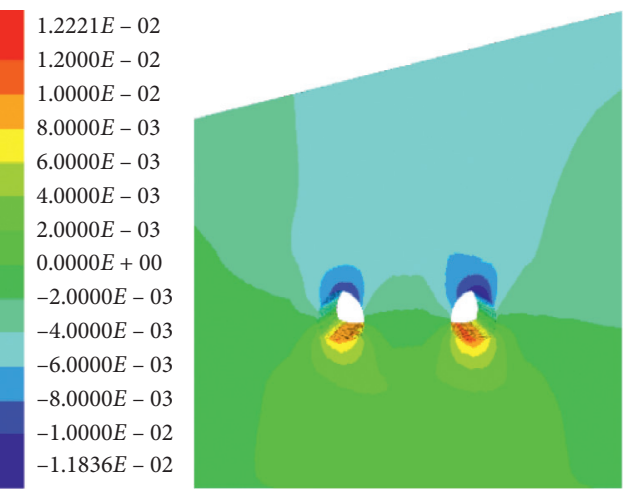

(b)

Z-displacement
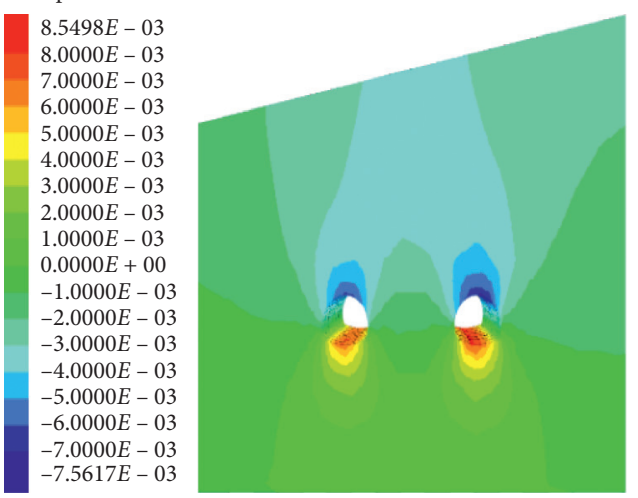

(d)

Z-displacement
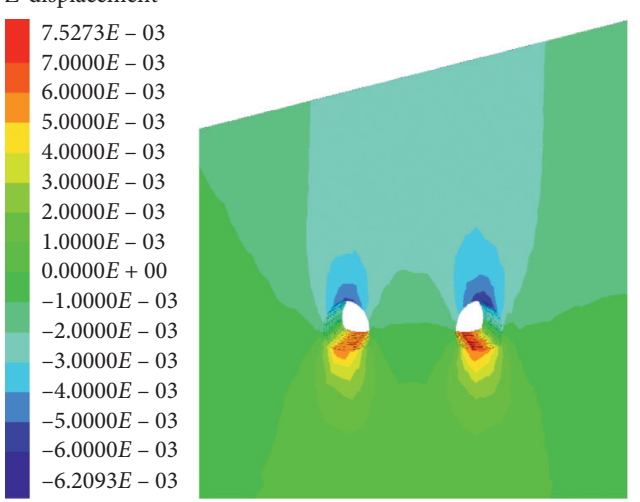

(f)

$Z$-displacement

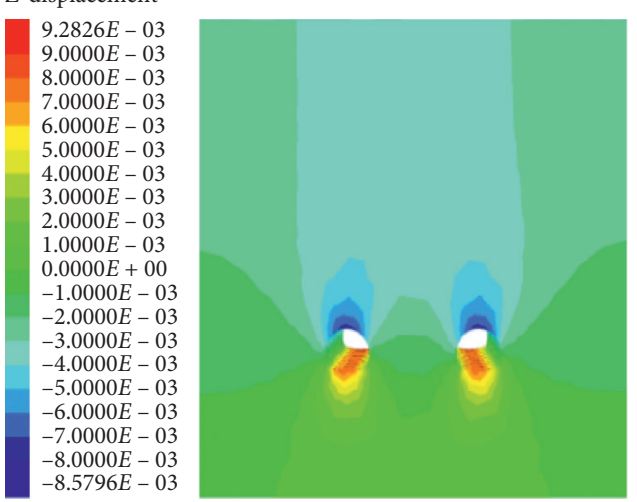

(h)

FIGURE 11: Z-direction displacement diagram of change with the thickness of the reverse dip rock layer. (a) Without bedding (terrain only). (b) Layer thickness is $0.5 \mathrm{~m}$. (c) Layer thickness is $1 \mathrm{~m}$. (d) Layer thickness is $2 \mathrm{~m}$. (e) Layer thickness is $3 \mathrm{~m}$. (f) Layer thickness is $4 \mathrm{~m}$. (g) Layer thickness is $5 \mathrm{~m}$. (h) Without bedding or topography. 


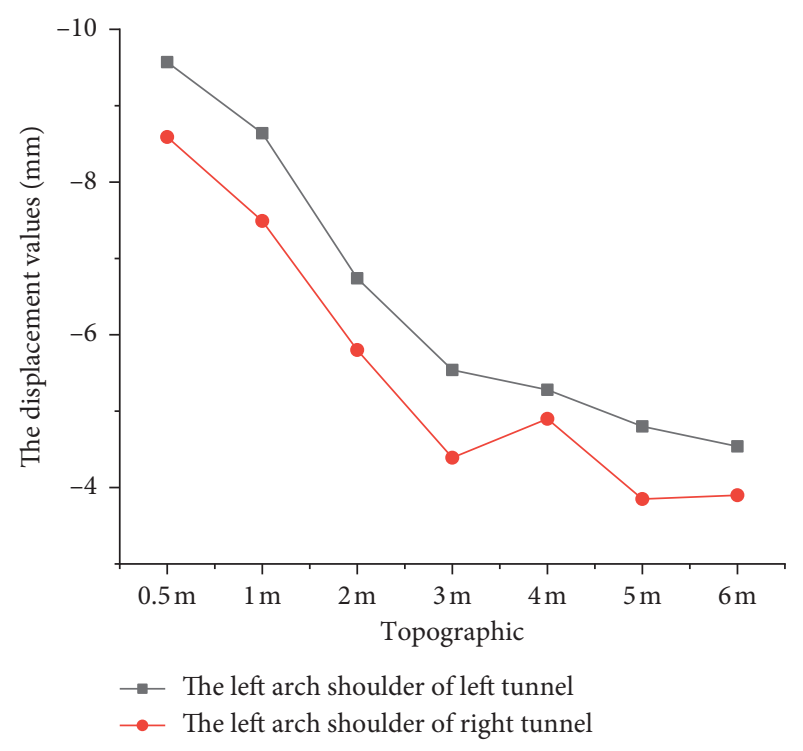

(a)

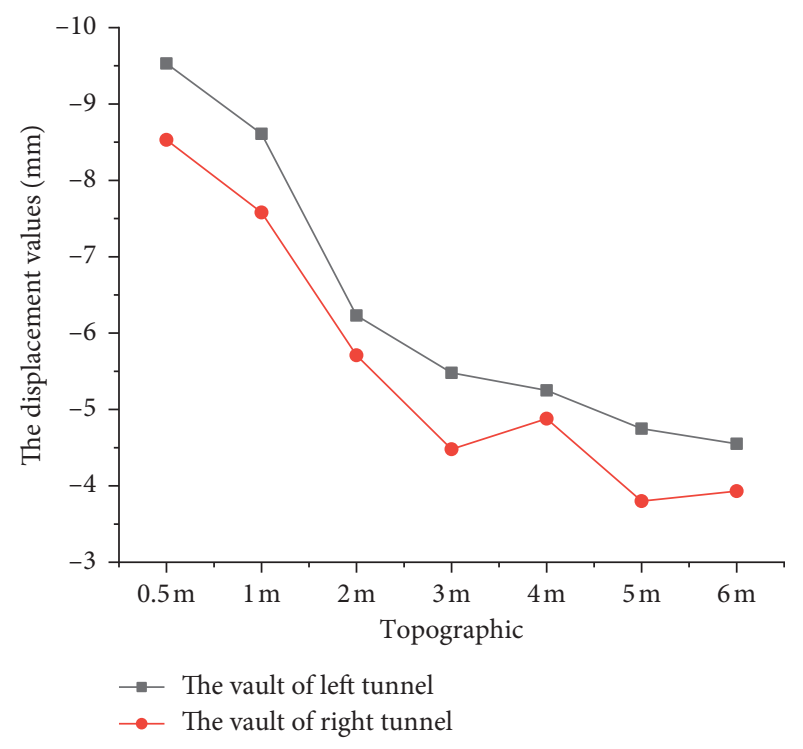

(c)

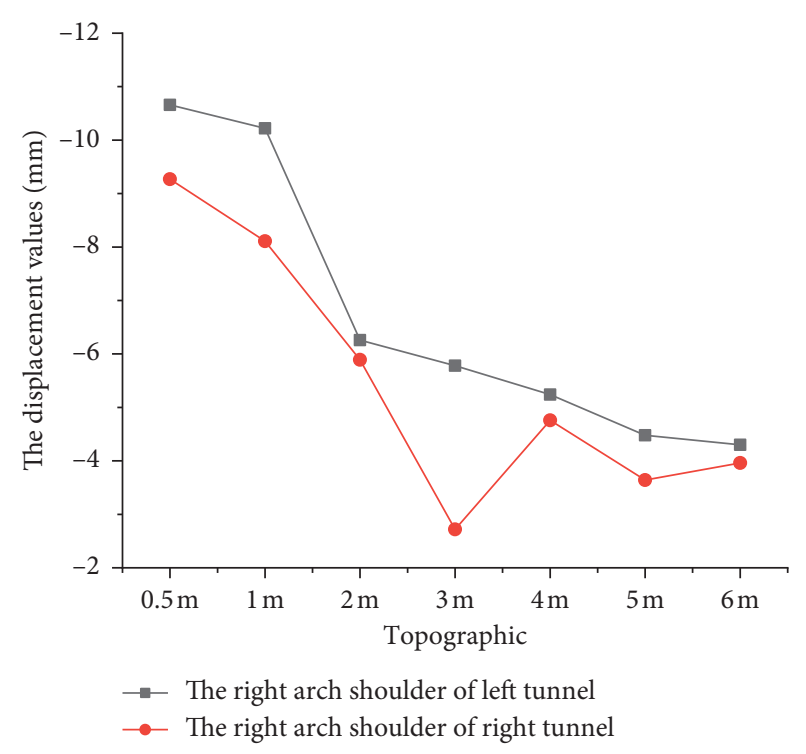

(b)

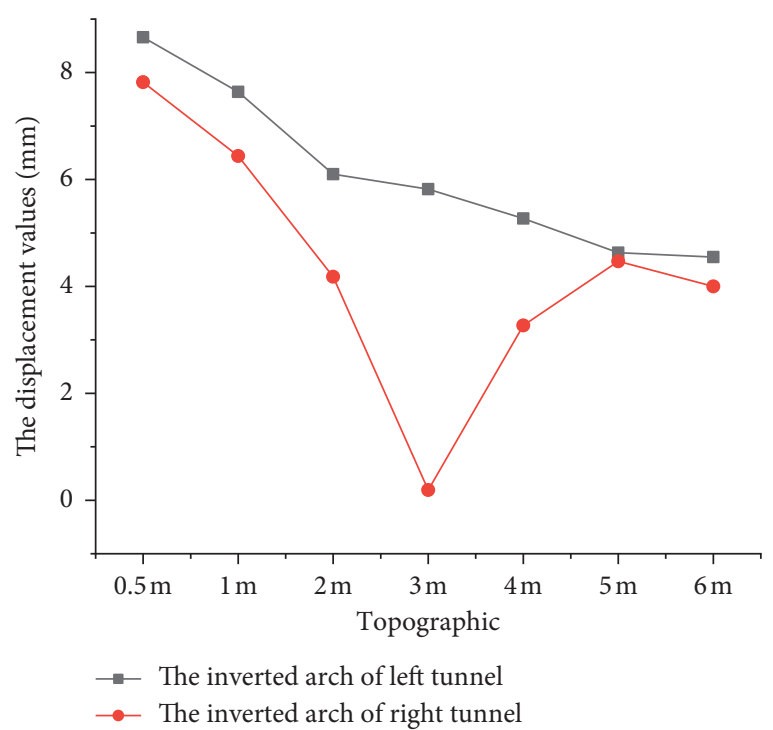

(d)

FIGURE 12: Comparison diagram of the $Z$ displacement of different monitoring points in the left and right tunnels. (a) Left arch shoulder. (b) Right arch shoulder. (c) Arch roof. (d) Inverted arch.

displacement value of each point increases with the decrease in the thickness of the rock layer. This finding shows that the geological bias offsets the topographic bias and is in the control position.

Based on the above analysis results, the following is obtained.

In the two walls of the tunnels, the $X$ displacement of the shallow buried side of the left tunnel is greater than that of the deep buried side of the right tunnel. The $Z$ displacements of the top and invert at the deep buried side of the right tunnel are both greater than those at the shallow buried side of the left tunnel.

The geological bias increases with decreasing bed thickness. When the layer thickness is $5 \mathrm{~m}$, the geological bias pressure by the bedding at the top and the invert of the tunnels is in the control position. When the layer thickness is no more than $4 \mathrm{~m}$, the geological bias pressure is in the control position at the left wall of the tunnels. When the layer thickness is less than $3 \mathrm{~m}$, the geological bias pressure is in the control position at the right arch waist of the tunnels. When the layer thickness of the right wall of the right tunnel is less than $2 \mathrm{~m}$ and the layer thickness of the right wall of the left tunnel is $5 \mathrm{~m}$, the geological bias pressure is in the control position.

The deformation analysis of the tunnel model under different rock layers used a slope angle of $11^{\circ}$, a dip angle of $10^{\circ}$, and a consequent dip. The deformation analysis of the tunnel model under different dip angles used a slope angle of $11^{\circ}$, a layer thickness of $1 \mathrm{~m}$, and a reverse dip. The deformation analysis of the tunnel model under different dip 
TABLE 8: Range analysis of the horizontal displacement of the slope angle point 7\# on the right wall of the right tunnel.

\begin{tabular}{|c|c|c|c|c|c|c|c|}
\hline No. & Displacement values (mm) & No. & Displacement values $(\mathrm{mm})$ & No. & Displacement values (mm) & No. & $\begin{array}{l}\text { Displacement } \\
\text { values }(\mathrm{mm})\end{array}$ \\
\hline 1 & -1.2273 & 5 & -26.5330 & 9 & -2.0191 & 13 & -1.0423 \\
\hline 2 & -36.8170 & 6 & -6.5455 & 10 & -2.1486 & 14 & -4.3525 \\
\hline 3 & -6.9216 & 7 & 0.6445 & 11 & -0.6158 & 15 & -0.1432 \\
\hline 4 & 8.6788 & 8 & 0.9236 & 12 & -1.0956 & 16 & -0.9323 \\
\hline Factor & 1 & 2 & 3 & 4 & 5 & & \\
\hline $\bar{K} 1$ & -9.0718 & -7.7054 & -2.3302 & -1.5077 & -0.6489 & & \\
\hline $\bar{K} 2$ & -7.8776 & -12.4659 & -16.1472 & -9.3879 & -9.7810 & & \\
\hline $\bar{K} 3$ & -1.4698 & -1.7590 & -3.0924 & -9.1339 & -3.9013 & & \\
\hline $\bar{K} 4$ & -1.6176 & 1.8936 & 1.5331 & 1.5331 & -5.7056 & & \\
\hline$R$ & 7.6020 & 14.3595 & 17.6803 & 10.9210 & 9.1321 & & \\
\hline
\end{tabular}

Note. 1 is the properties of the rock mass and structural plane; 2 is the thickness of the rock layer; 3 is the rock dip angle; 4 is the slope angle; and 5 is the buried depth of the tunnel.

angles used a slope angle of $11^{\circ}$, a layer thickness of $1 \mathrm{~m}$, and a consequent dip. The deformation analysis method of the tunnel model under different rock layers used a slope angle of $11^{\circ}$, a dip angle of $10^{\circ}$, and a reverse dip. There was no need to interpret each method one by one.

\subsection{Analysis of Different Factors by Orthogonal Experiment.} The radar diagram and correlation analysis of the simulation results by orthogonal experiment and range analysis in the forward-leaning rock formations are as follows.

Taking the range analysis of the horizontal displacement of the slope angle point $7 \#$ on the right wall of the right tunnel as an example, by the range analysis results in Table 8 , $R_{3}>R_{2}>R_{4}>R_{5}>R_{1}$; in other words, the rock dip angle and the thickness of the rock layer have the greatest influence on the deep buried side of the right wall of the right tunnel, followed by the slope angle, the buried depth of the tunnel, and the properties of the rock mass and structural plane, as shown in the blue line in Figure 13(a).

The radar chart representation and correlation analysis of the simulation results of the orthogonal experiment and the range analysis of the consequent dip are shown in Figure 13.

As shown in Figure 13, each monitoring point of the two walls of the right cave (deep buried side) was affected to different degrees by each factor. The main influencing factor of the left arch waist and right wall is the rock dip angle. The left arch waist and the right wall are mainly affected by the rock dip angle. The main influencing factors of the right arch waist and the left wall are the properties of the rock mass and structural plane. Each monitoring point of the top of the right cave (deep buried side) was affected first by the properties of the rock mass and structural plane and second by the layer thickness and the slope angle.

As shown in Figure 14, each monitoring point of the two walls of the left cave (shallow buried side) was affected to consistent degrees by each factor. The main influencing factor of the left and right arch waist and the left and right wall is the layer thickness of the rock. Other factors also contribute greatly to the deformation. The buried depth of the tunnel has the least influence on the displacement change of each monitoring point. Each monitoring point of the top of the left cave (shallow buried side) was affected mainly by the slope angle.

Figure 15 shows that the primary factors that affect the deformation of the inverted arch of the left and right caves are only the properties of the rock mass and structural plane, while other factors have little impact on the deformation.

In summary, the control index of bias deformation of the tunnel in the consequent dip and layered rock mass was studied by using the analysis method through an orthogonal experiment. The deformation of the deep buried side tunnel is mainly affected by the properties of the rock mass and structural planes. The deformation of the two walls of the shallow buried tunnel is mainly affected by the layer thickness of the rock, and the deformation of the top of the tunnel is mainly affected by the slope angle. The deformation of the inverted arch in both the left and the right tunnel is mainly controlled by the properties of the rock mass and structural planes.

3.3. Analysis of Construction Deformation Control and Optimization. The optimal excavation sequence was studied under three working conditions, namely, topographic bias of forward-leaning rock, topographic bias of backward-leaning rock, and geological bias of backward-leaning rock. The influence of the bolt length and bolt angle on the tunnel deformation of the layered rock mass is summarized as follows.

3.3.1. Construction Sequence. The optimal construction sequence is summarized from the numerical simulation results under different working conditions and is given in Table 9.

3.3.2. Anchor Rod Length. Figure 16 shows a comparison of the displacement values of key points in the numerical simulation results when the anchor rod length is changed.

As shown in Figure 16, from the numerical simulation results, it can be seen that the displacement of the arch roof of the left and right tunnel and the left and right arch shoulder of the left and right tunnel decreases first and then 


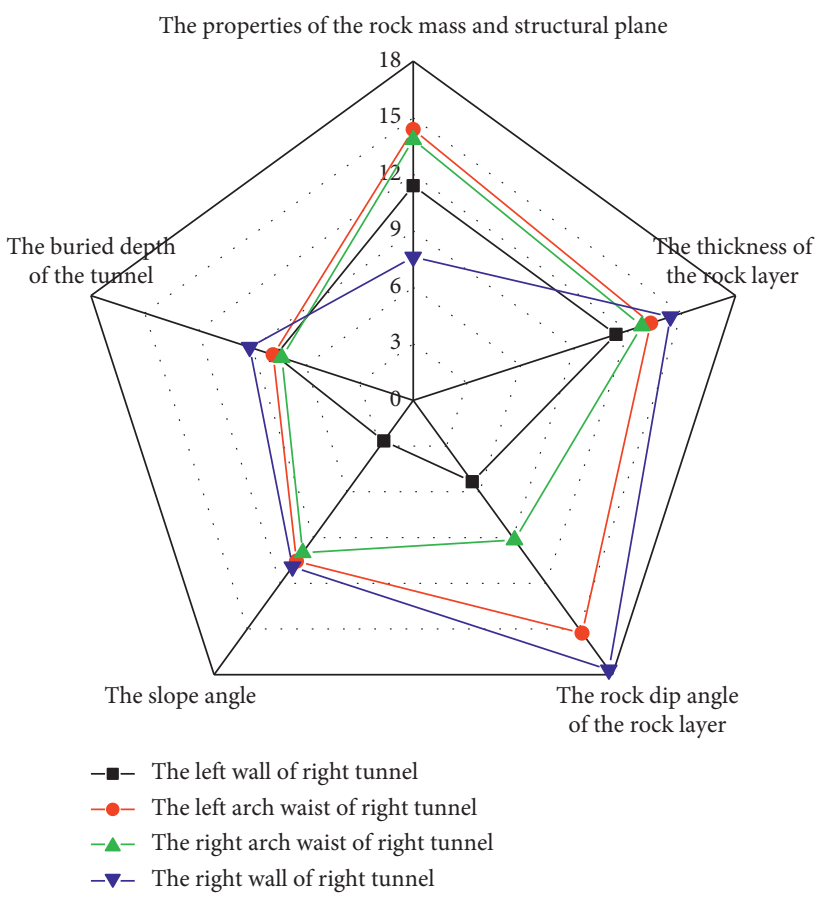

(a)

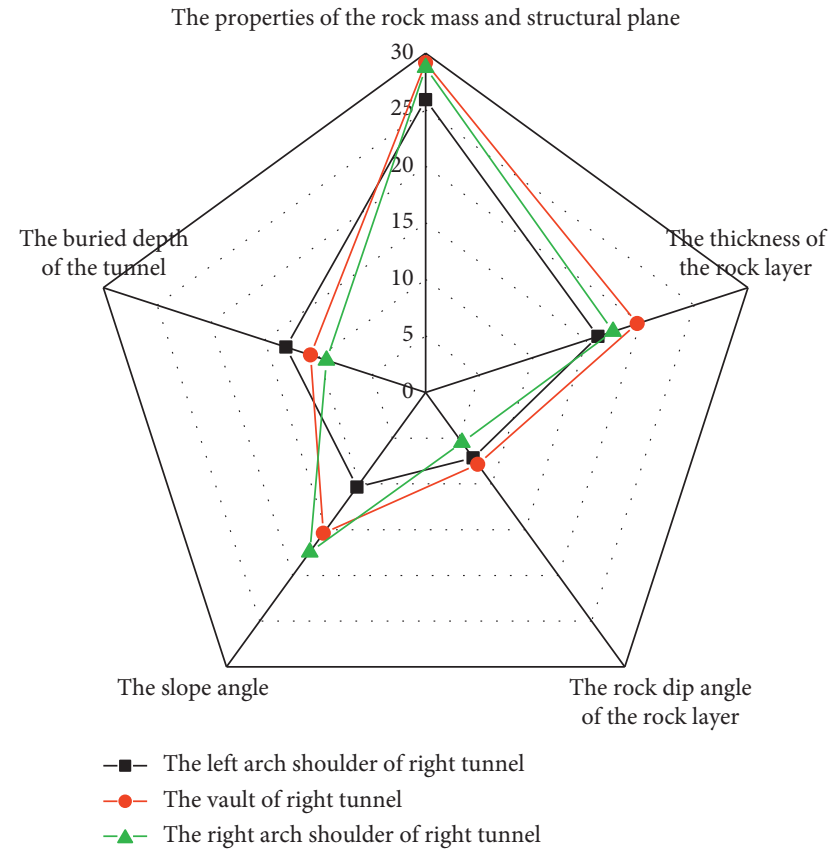

(b)

Figure 13: Radar map of the influence degree of each factor on the right cave (deep buried side). (a) Radar map of the influence degree of each factor on the two walls of the right cave (deep buried side). (b) Radar map of the influence degree of each factor on the top of the right cave (deep buried side).

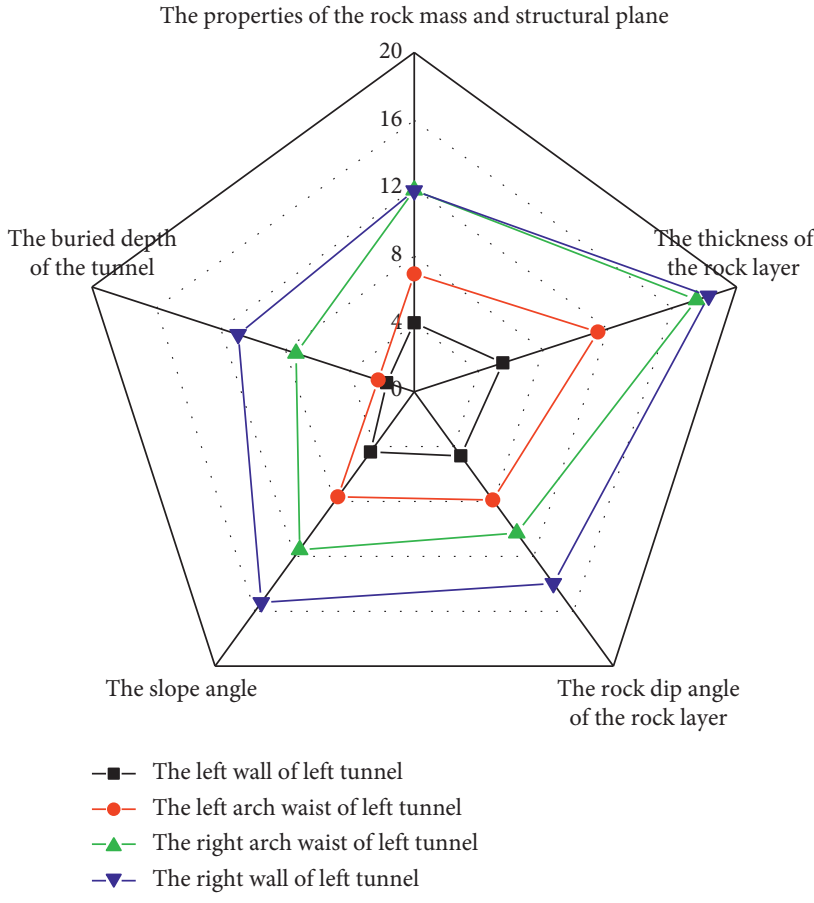

(a)

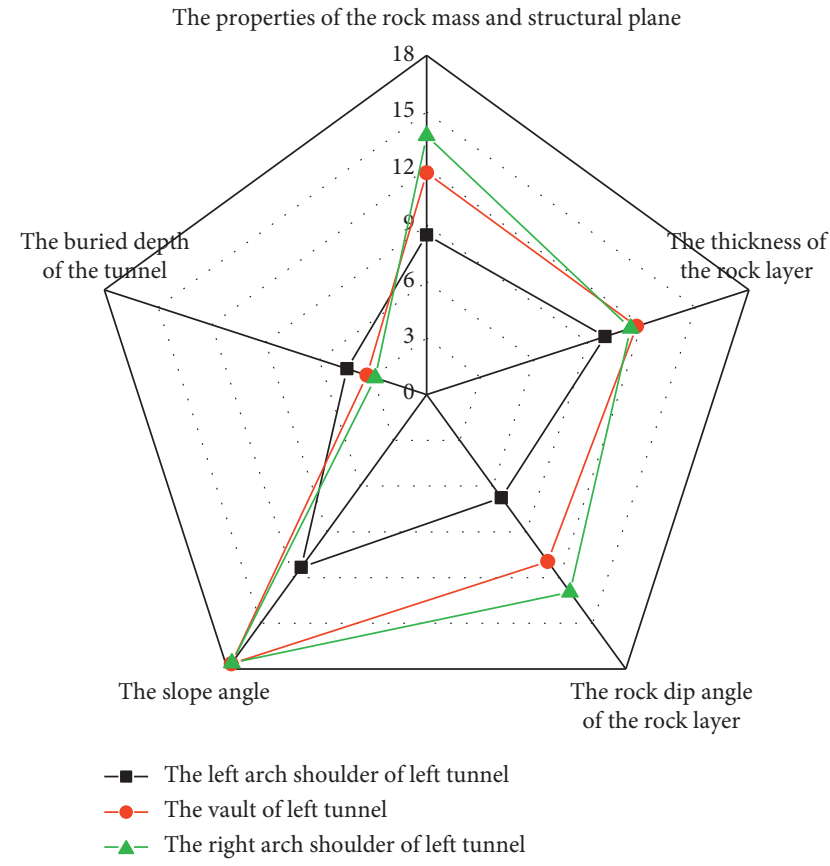

(b)

FIGURE 14: Radar map of the influence degree of each factor on the right cave (shallow buried side). (a) Radar map of the influence degree of each factor on the two walls of the left cave (shallow buried side). (b) Radar map of the influence degree of each factor on the top of the left cave (shallow buried side). 


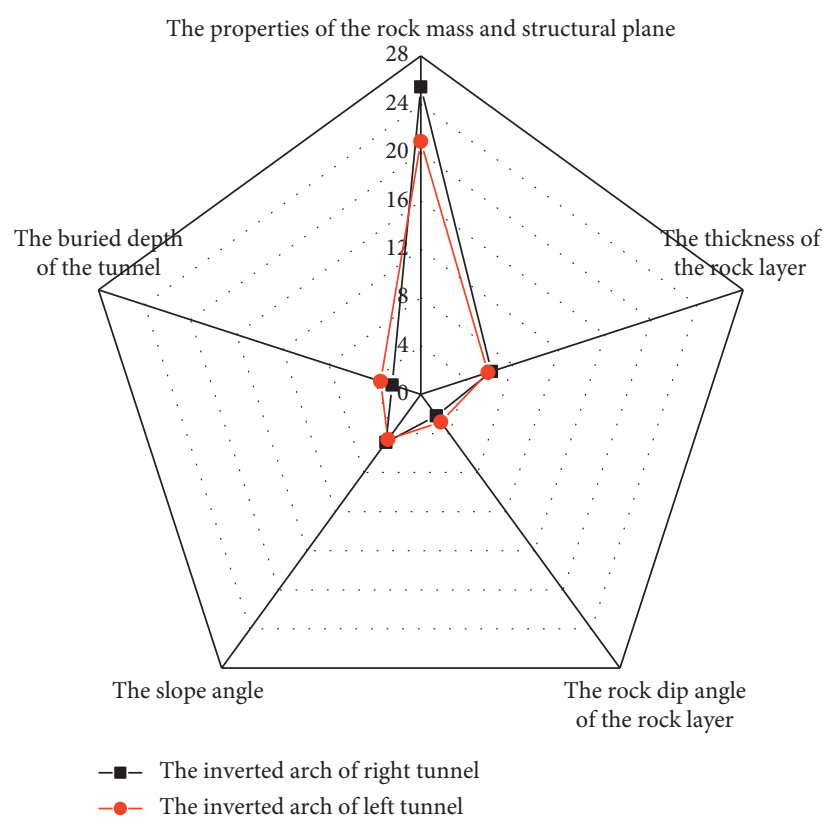

FIGURE 15: Radar map of the influence degree of each factor on the inverted arch of the left and right cave.

TABLe 9: Optimal excavation sequence under different working conditions.

Working condition

Consequent dip rock

Reverse dip rock under topographic factor control

Reverse dip rock under geological factor control

\section{Excavation sequence}

Shallow buried side before deep buried side (first left then right)

Shallow buried side after deep buried side (first right then left)

Shallow buried side before deep buried side (first left then right)

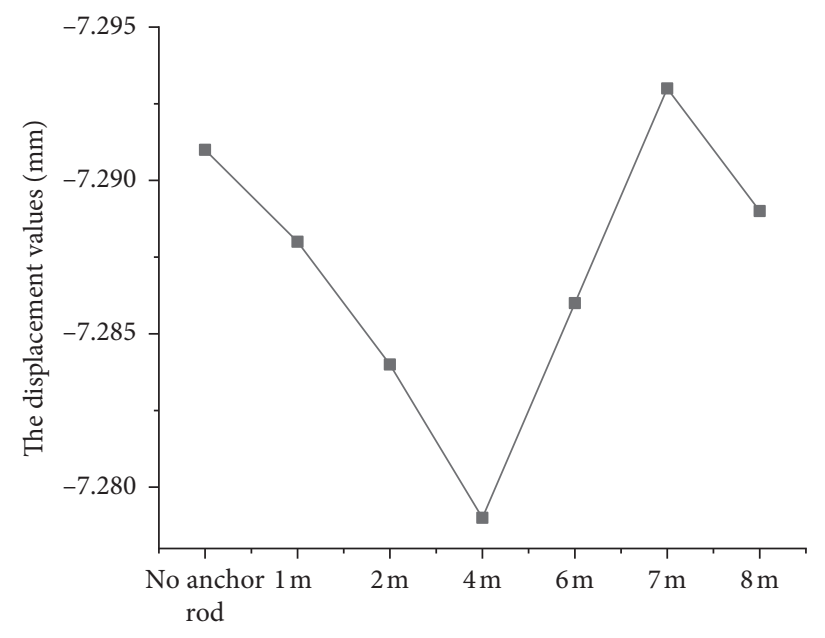

$\rightarrow$ The vault of left tunnel

(a)

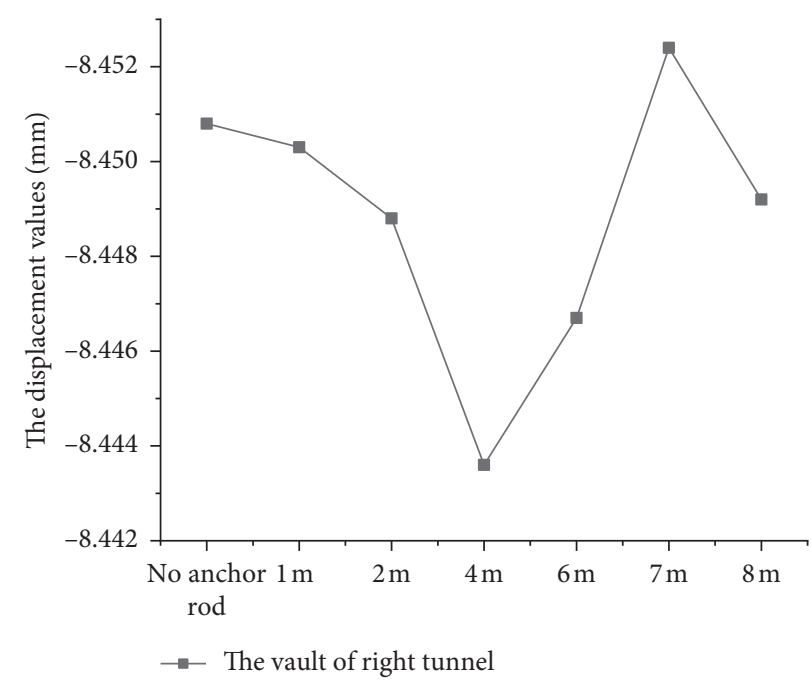

(b)

Figure 16: Continued. 


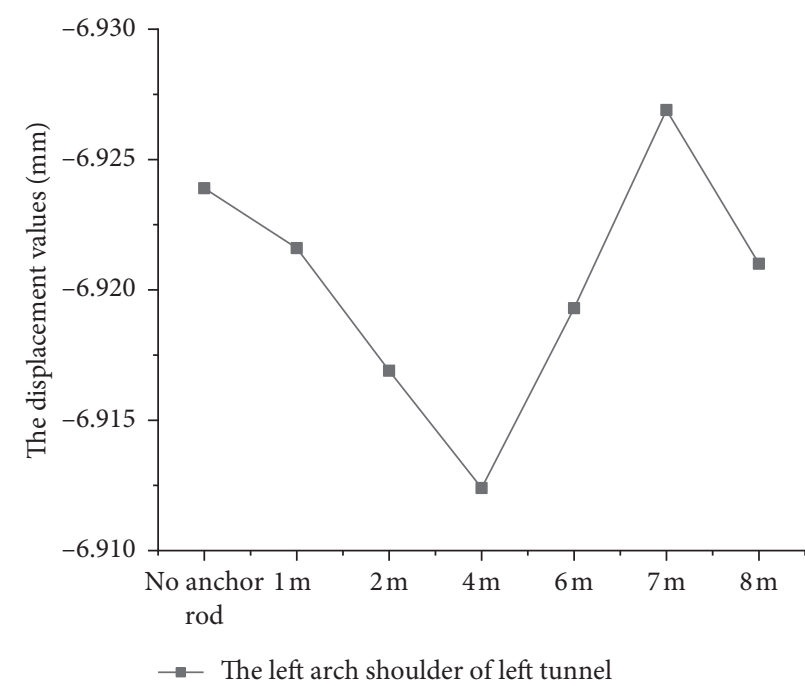

(c)

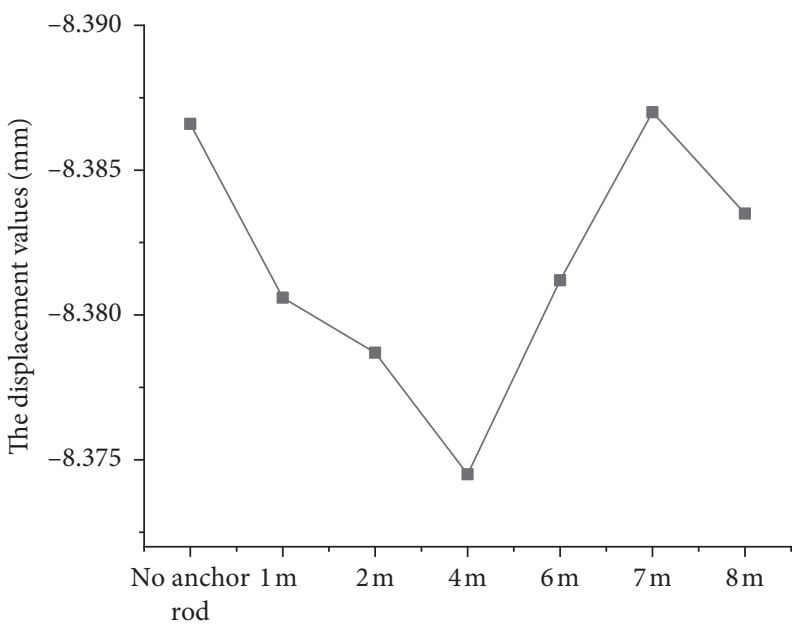

- The right arch shoulder of left tunnel

(e)

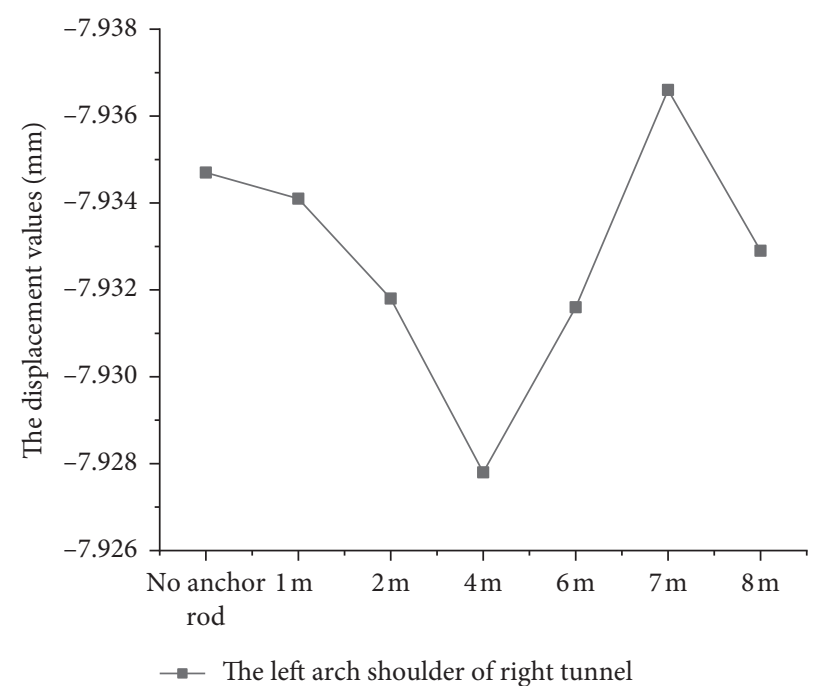

(d)

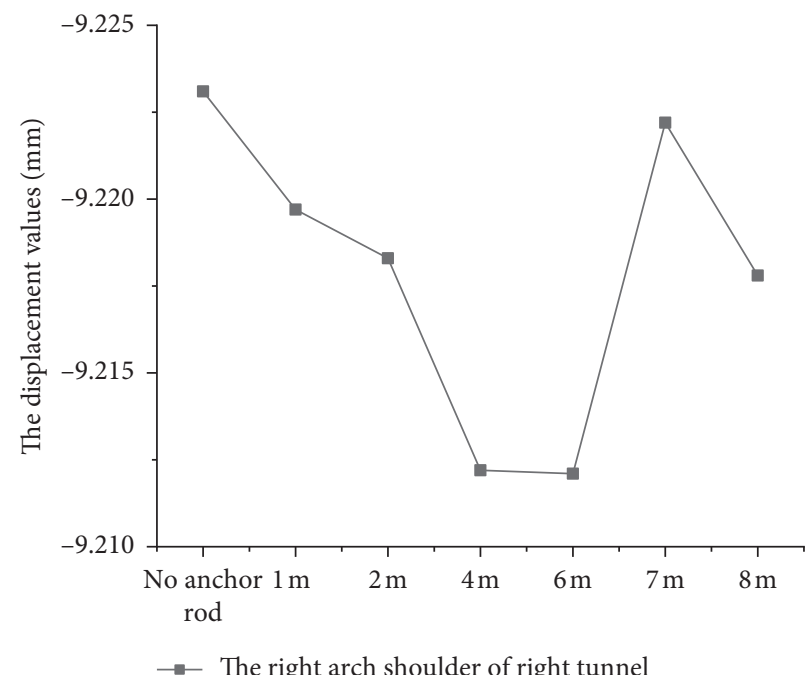

(f)

FIGURE 16: Influence comparison chart of the bolt length on displacement.

increases with the increase in the anchor rod length. The displacement is the smallest when the anchor rod length is $4 \mathrm{~m}$. When the anchor rod length increases to more than $7 \mathrm{~m}$, the displacement decreases as the bolt length increases again. This finding indicates that there is an optimal anchor rod length, and a longer length is not necessarily better. The optimal supporting length of the anchor rod in this model is $4 \mathrm{~m}$.

The exception in Figure 16 is that the displacement of the right arch shoulder of the right tunnel reaches its minimum when the bolt length is $6 \mathrm{~m}$. The reason is that the selected research model itself has topographic bias, and thus a longer bolt is needed. It can also be concluded that the greater the deformation of the tunnel, the longer the required anchor rod length.

3.3.3. Anchor Rod Angle. The numerical simulation results show that the radial bolt arrangement can lead to a smaller deformation compared with other bolt arrangements when the bolt length is fixed. Part of the bolt is arranged perpendicular to the layered rock mass, which can reduce the displacement of the surrounding rock. For the position where the local deformation is greater, the deformation control of the surrounding rock can be conducted comprehensively by local adjustment of the anchor rod angle and layout spacing on the basis of the radial arrangement.

\section{Discussion and Conclusions}

Bias tunnel deformation has a large adverse effect on the tunnel construction and induces disasters such as uneven settlement and rock burst, resulting in substantial economic losses and life and property losses. Therefore, appropriate measures should be taken to control the bias deformation during tunnel construction. The research conclusions of this paper are as follows: 
(1) The monitoring data and the analysis of the deformation characteristics of the surrounding rock show that the settlement deformation of the vaults of the left and right tunnels shows obvious bias characteristics. Based on the mechanism of bias, there are three reasons for this bias. The first is geological bias. The second is terrain bias. The third is that the buried depth of the left tunnel is shallow and is excavated first, which has an unloading effect on the rock mass of the right tunnel, leading to the larger deformation of the right tunnel.

(2) After the analysis of the four groups of models was completed, the structural parameters (layer thickness and dip angle) of the consequent dip rock and the reverse dip rock in the double tunnel layered rock mass were summarized. The deformation rules of the biased tunnel caused by the layer thickness and the dip angle are as follows:

(i) When the rock layer thickness is less than a certain value (approximately $5 \mathrm{~m}$ ), the deformation of the left and right cavities increases with the decrease in the rock layer thickness. When the rock layer thickness is less than $1 \mathrm{~m}$, the degree of surrounding rock fragmentation is high, with an approximately homogeneous body, and the deformation decreases. The surrounding rock deformation of the reverse dip rock is controlled by a combination of topographic bias and geological bias, and the deformation of the surrounding rock of the consequent dip rock is influenced by geological bias and topographic bias together. When the deformation of the surrounding rock increases, the degree of bias increases.

(ii) As the thickness of the rock layer changes, in the reverse dip rock, the deformation of the two walls of the left tunnel is greater than that of the right tunnel, and the deformation of the arch roof and the inverted arch of the right tunnel is greater than that of the left tunnel; in the consequent dip rock, the deformation of the right tunnel is greater than that of the left tunnel. In brief, the surrounding rock deformation of the reverse dip rock is controlled by a combination of topographic bias and geological bias; the surrounding rock deformation of the consequent dip rock is influenced by geological bias and topographic bias together.

(iii) As the dip angle of the layer changes, when the dip angle of the layer is less than $45^{\circ}$, the deformation of the left wall of the left tunnel is greater than that of the right tunnel; when the dip angle of the layer is no less than $45^{\circ}$, the deformation of the left wall of the right tunnel is greater than that of the left tunnel. When the dip angle of the layer is less than $90^{\circ}$, the deformation of the right wall of the left tunnel is greater than that of the right tunnel. When the dip angle of the layer is $90^{\circ}$, the deformation of the right tunnel is greater than that of the left tunnel, and the surrounding rock deformation of the arch roof and the inverted arch in the right tunnel is greater than that of the corresponding position in the left tunnel.

(3) The orthogonal test results show that the main influencing factors of the different position deformations in the left and right tunnels in the layered rock mass tunnels are different. The main factors that influence the deformation in the deep buried side tunnel are the properties of the rock mass and the structural plane. However, the positions of the left arch waist and the right wall are mainly affected by the dip angle of the layer. The main factor that affects the deformation of the two walls of the shallow buried side tunnel is the layer thickness. The main influencing factor of vault roof deformation is the slope angle. The deformation of the left and right tunnel inverted arch is controlled by the properties of the rock mass and structural plane.

(4) Through the numerical simulation of different models, the optimal excavation sequence, the optimal bolt supporting length, and the optimal bolt layout method under different working conditions were summarized. The research conclusions are as follows:

(i) The shallow buried side is first excavated and then the deep buried side is excavated under the working condition of consequent dip rock. The deep buried side is first excavated, and then the shallow buried side is excavated under the working condition of reverse dip rock under topographic factor control. The shallow buried side is first excavated, and then the deep buried side is excavated under the working condition of reverse dip rock under geological factor control.

(ii) For the anchor rod length, it is not the case that the longer, the better; instead, there is an optimal anchor rod length that achieves the best supporting effect. The optimal supporting length of the anchor rod in these models is $4 \mathrm{~m}$.

(iii) When the anchor rod length is constant, the radial anchor rod arrangements can control the deformation better than other anchor rod arrangements. For some bolted rods, the placement of being perpendicular to layered rock mass can reduce the displacement of the surrounding rock. For a position with a large deformation, it can be treated by transforming the anchor rod angle on the basis of a radial arrangement. In addition, it can be combined with changing the anchor rod length and adjusting the layout spacing of the anchor rod to control the deformation of the surrounding rock. 


\section{Data Availability}

All the data, models, and code generated or used during the study are included in the article.

\section{Conflicts of Interest}

The authors declare that they have no conflicts of interest.

\section{Acknowledgments}

The authors gratefully acknowledge the financial support provided by the National Key Research and Development Project of China, the Ministry of Science and Technology of China (no. 2018YFC1505504).

\section{References}

[1] S. M. Tian and J. F. Gong, "Statistics of Railway tunnels in China by the end of 2019," Tunnel Construction (Chinese and English), vol. 40, no. 2, pp. 292-297, 2020.

[2] J. X. Yan, "40 years of development of Tunnel engineering technology in China," Tunnel Construction (Chinese and English), vol. 39, no. 4, pp. 537-544, 2019.

[3] T. Feng, L. W. Jiang, C. D. Wang et al., "Application of engineering geological analogy method in the classification of surrounding rocks of sichuan-tibet railway tunnel," Sichuan Architecture, vol. 37, no. 2, pp. 139-141, 2017.

[4] T. Feng, L. W. Jiang, G. Z. Zhang et al., "Discussion on evaluation method of water and heat damage in yakang section of sichuan-tibet railway," Journal of Railway Engineering, vol. 33, no. 5, pp. 11-17, 2016.

[5] X. Q. Zhong, "Model test analysis of soil bias tunnel lining," Journal of Southwest Jiaotong University, vol. 6, pp. 28-32, 1996.

[6] L. Guo, J. C. Li, Z. C. Zhang et al., "Research and application of geo-radar in detecting surrounding rock loose zone of bias pressure tunnel," Chinese Journal of Rock Mechanics and Engineering, vol. 30, no. S1, pp. 3009-3015, 2011.

[7] S. Y. Chen, Y. P. Zhu, Z. Li et al., "Analysis on the influence of lateral slope stability of large section loess bias tunnel excavation," Modern Tunnel Technology, vol. 51, no. 01, pp. 82-89, 2014.

[8] X. Liu, S. Wang, S. Wang, and E. Wang, "Fluid-driven fractures in granular materials," Bulletin of Engineering Geology and the Environment, vol. 74, no. 2, pp. 621-636, 2015.

[9] C. Y. Cao, C. H. Shi, L. M. Peng et al., "Study on risk assessment and control measures of shallow buried large span undercrossing expressway tunnel construction," Journal of Railway Science and Engineering, vol. 13, no. 07, pp. 14391446, 2016.

[10] Q. Y. Yu, W. Liu, L. Nai et al., "Analysis of bias stress ratio characteristics of bias tunnel," Journal of Jilin University (Earth Science Edition), vol. 48, no. 6, pp. 1797-1803, 2018.

[11] S. L. Dai, Y. Z. Wan, and Y. C. Zhang, "Study on stability of bias tunnel," Exploration Engineering (Rock and Soil Drilling and Excavation Engineering), vol. 46, no. 9, pp. 99-103, 2019.

[12] F. Wang, H. M. Tang, Y. B. Ning et al., "Deep toppling stability evaluation of interbedded slope based on evolution process," Geological Science and Technology Information, vol. 38, no. 5, pp. 186-194, 2019.
[13] Z. Q. Zhang and C. He, "Study on optimal construction of bias arch tunnel," Rock and Soil Mechanics, vol. 4, pp. 723-732, 2007.

[14] B. Hu, H. B. Zhao, S. J. Wang et al., "Pull-out model test for tunnel anchorage and numerical analysis," Rock and Soil Mechanics, vol. 30, no. 6, pp. 1575-1582, 2009.

[15] M. F. Lei, L. M. Peng, C. H. Shi et al., "Experimental study on mechanical characteristics and failure mechanism of shallowburied tunnel lining with bias pressure," Journal of Central South University (Science and Technology), vol. 44, no. 8, pp. 3316-3325, 2013.

[16] H. P. Lai, W. J. Yang, and Y. L. Xie, "Deformation and load action characteristics of highway tunnel with large deformation and bias pressure in soft rock," Journal of Central South University (Science and Technology), vol. 45, no. 6, pp. 1924-1931, 2014.

[17] J. X. Lai, H. B. Fan, H. P. Lai et al., "Field test and analysis of deformation law of tunnel in soft loess," Rock and Soil Mechanics, vol. 36, no. 07, pp. 2003-2020, 2015.

[18] X. Wei, X. Liu, Y. Duan, and J. Feng, "Property transformation of a modified sulfoaluminate grouting material under pressure circulation for a water-sealed underground oil cavern," Construction and Building Materials, vol. 140, pp. 210-220, 2017.

[19] M. H. Jin, D. L. Li, X. R. Liu et al., "Study on the reserved deformation of loess tunnel with different slope and bias pressure," Modern Tunnel Technology, vol. 54, no. 1, pp. 130-137, 2017.

[20] X. Liu, G. Han, E. Wang, S. Wang, and K. Nawnit, "Multiscale hierarchical analysis of rock mass and prediction of its mechanical and hydraulic properties," Journal of Rock Mechanics and Geotechnical Engineering, vol. 10, no. 4, pp. 694-702, 2018.

[21] X. Liu, F. Wang, J. Huang, S. Wang, Z. Zhang, and K. Nawnit, "Grout diffusion in silty fine sand stratum with high groundwater level for tunnel construction," Tunnelling and Underground Space Technology, vol. 93, Article ID 103051, 2019.

[22] W. X. Huang, H. Wu, J. Wang et al., "Comparative study on excavation sequence of weak surrounding rock with bias pressure," Journal of Engineering Geology, vol. 27, no. 2, pp. 277-285, 2019.

[23] W. Hu, Y. Yu, X. R. Tan et al., "Study on failure characteristics and support measures of bedding bias tunnel," Chinese Journal of Underground Space and Engineering, vol. 16, no. S1, pp. 450-510, 2020.

[24] G. Z. Sun, "On rock mass mechanics model," Geological Science, no. 04, pp. 423-428, 1984. 